\title{
Uranium-series dating and growth characteristics of the deep-sea scleractinian coral: Enallopsammia rostrata from the Equatorial Pacific
}

\author{
Fanny Houlbrèque $^{\mathrm{a}, \mathrm{b}, *}$, Malcolm McCulloch ${ }^{\mathrm{c}, \mathrm{d}}$, Brendan Roark ${ }^{\mathrm{e}}$, Tom Guilderson ${ }^{\mathrm{f}}$, \\ Anders Meibom ${ }^{\mathrm{g}}$, Justine Kimball ${ }^{\mathrm{a}}$, Graham Mortimer ${ }^{\mathrm{c}}$, Jean-Pierre Cuif ${ }^{\mathrm{h}}$, \\ Robert Dunbar ${ }^{a}$ \\ ${ }^{a}$ Geological and Environmental Sciences, Stanford University, Stanford, CA 95064, USA \\ ${ }^{\mathrm{b}}$ International Atomic Energy Agency, Marine Environment Laboratories, MC 98012 Monaco, Monaco \\ ${ }^{\mathrm{c}}$ Research School of Earth Sciences, Australian National University, Canberra, ACT, Australia \\ ${ }^{\mathrm{d}}$ School of Earth and Environment and ARC Centre of Excellence in Coral Reef Studies, University of Western Australia, Crawley, \\ Western Australia 6009, Australia \\ ${ }^{\mathrm{e}}$ Texas A\&M University, Department of Geography, Ocean Drilling \& Sustainable Earth Science, College Station, TX 77843, USA \\ ${ }^{\mathrm{f}}$ Center for Accelerator Mass Spectrometry, LLNL, L-397 7000 East Avenue, Livermore, CA 94551, USA \\ ${ }^{\mathrm{g}}$ UMR 8148, Interactions et Dynamique des Environnement de Surface, Université Paris XI, Orsay, France \\ ${ }^{\mathrm{h}}$ Laboratoire d'Étude de la Matière Extraterrestre USM 0205, Muséum National d'Histoire Naturelle, Paris, France
}

Received 20 January 2009; accepted in revised form 13 January 2010; available online 20 January 2010

\begin{abstract}
The deep-sea coral, Enallopsammia rostrata, a member of the Dendrophylliidae family, is a major structure-forming species that creates massive dendroid colonies, up to $1 \mathrm{~m}$ wide and $0.5 \mathrm{~m}$ tall. Living colonies of E. rostrata have been collected using the PISCES submersibles from three locations from 480 to $788 \mathrm{~m}$ water depth in the Line Islands $\left(\sim 160^{\circ} \mathrm{W}\right)$ in the Equatorial Pacific. We have applied to these colonies a high sensitivity, low blank technique to determine U-series ages in small quantities ( $70 \pm 15 \mathrm{mg}$ ) of modern and near modern calcareous skeletons using MC-ICP-MS (Multi-collector Inductively Coupled Plasma Mass Spectrometer). The application of this method to living slow-growing colonies from a range of sites as well as the observations of axial growth patterns in thin sections of their skeletons offer the first expanded and well constrained data on longevity, growth pattern and mean growth rates in E. rostrata. Absolute dated specimens indicate life spans of colonies ranging from $209 \pm 8$ yrs to $605 \pm 7$ yrs with radial growth rates from 0.012 to $0.072 \mathrm{~mm} \mathrm{yr}^{-1}$ and vertical extension rates from 0.6 to $1.9 \mathrm{~mm} \mathrm{yr}^{-1}$. The linear growth rates reported here are lower than those reported for other deep-sea scleractinian corals (Lophelia pertusa and Madrepora oculata). The U-series dating indicates that the growth ring patterns of E. rostrata are not consistent with annual periodicity emphasizing the importance of absolute radiometric dating methods to constrain growth rates. Slow accretion and extreme longevity make this species and its habitat especially vulnerable to disturbances and impacts from human activities. This dating method combined with observation of growth patterns opens up new perspectives in the field of deep-sea corals since it can provide quantitative estimates of growth rates and longevity of deep-sea corals in general.
\end{abstract}

(C) 2010 Elsevier Ltd. All rights reserved.

\footnotetext{
* Corresponding author. Address: Geological and Environmental Sciences, Stanford University, Stanford, CA 95064, USA. Tel.: +1 37797977258

E-mail address: F.Houlbreque@iaea.org (F. Houlbrèque).
}

\section{INTRODUCTION}

Deep-water corals have been known by fishermen and benthic specialists for centuries (Zibrowius, 1980). However, 
only recently, as fishery and oil exploration activities have expanded into deeper waters, together with developments in acoustic survey techniques and access to submersibles, have the scale and widespread abundance of these coldwater ecosystems been revealed (Freiwald et al., 2004; Roberts et al., 2005). Deep-water corals provide high relief habitats for a number of ecologically important species of invertebrates and fishes (Marshall, 1979; Mortensen et al., 1995; Risk et al., 1998). Direct and indirect degradation of deep-water coral ecosystems stems from a wide range of human activities. Most notable is the damage to deep-water coral ecosystems from trawling that has been observed in many areas around the globe (Probert et al., 1997; Koslow and Gowlett-Jones, 1998; Rogers, 1999; Bett, 2001; Hall-Spencer et al., 2002). Fishing pressures, oil and gas production, cable laying, mining and coral harvesting can also negatively impact these reefs (Rogers, 1999; Bett, 2001; Reed and Ross, 2005). Although the deep ocean is known for its relatively stable temperature and salinity, deep-water reef ecosystems are tightly coupled to surface water productivity and ecosystem dynamics (Duineveld et al., 2004; Roark et al., 2005; Thiem et al., 2006; Maier et al., 2009). Thus, it is likely that deep-water corals and their ecosystems will be impacted by climate change through surface water changes (Guinotte et al., 2006) as well as direct changes in their ambient environment by. In particular the calcium carbonate secreting deep-water corals will be affected by ocean acidification and the commensurate changes in alkalinity and carbonate ion content that will transpire as the carbonate saturation horizon rises. Indeed, many deep-water coral inhabit areas that already have low levels of calcium carbonate saturation so they may soon be unable to make their carbonate skeletons (Orr et al., 2005; Guinotte et al., 2006; Maier et al., 2009). In this context, constraints on growth rate, size, skeletal structure and age of deep-sea coral species are urgently needed to assess possible human impacts.

Like their shallow-dwelling counterparts, deep-sea corals have also proven to be important archives of past ocean variability. The isotopic and elemental composition of their skeletons is a useful archive for paleoceanographic reconstructions, providing information about deep ocean ventilation on timescales of decades to millennia (Adkins et al., 1998; Mangini et al., 1998; Smith et al., 2000; Weinbauer et al., 2000; Goldstein et al., 2001; Heikoop et al., 2002; Thresher et al., 2004). Also like their symbiont bearing shallow-water relations, deep-sea corals have skeletal bands that, if verified as annual, could be used for sclerochronology.

Independent methods to date deep-sea corals include sclerochronology, radiometric, or isotopic techniques. If one accurately knows the timing of band formation, counting growth rings in skeletons can be used to determine the age of a coral (Grigg, 1974; Mitchell et al., 1993; Mistri and Ceccherelli, 1994; Sherwood et al., 2005). Similar to studies of tropical reef-building corals (e.g., Fairbanks and Dodge, 1979) carbon and oxygen isotopic variations (Omura, 1983), may also have a seasonal cycle, which could provide a means to date deep-sea corals. However these approaches require independent validation and as will be shown in this study, banding in deep-sea corals does not appear to be controlled by predictable annual seasonal cycles. The most utilized independent methods include radiocarbon (Druffel et al., 1995; Risk et al., 2002; Roark et al., 2005, 2006; Noé and Dullo, 2006), ${ }^{210} \mathrm{~Pb}$ (Druffel et al., 1990; Andrews et al., 2002), or Ra-Th (Cheng et al., 2000; Adkins et al., 2002, 2004) dating. For corals, which have significant uranium concentrations in their carbonate skeleton, the ${ }^{234} \mathrm{U}-{ }^{230} \mathrm{Th}$ disequilibrium method has become one of the most utilized dating methods (Edwards et al., 1987; Bard et al., 1990; Adkins et al., 1998; Lomitschka and Mangini, 1999; Cheng et al., 2000; Goldstein et al., 2001). This method is based on the radioactive decay chain from the parent ${ }^{238} \mathrm{U}$, via the intermediate isotope ${ }^{234} \mathrm{U}$ and the daughter ${ }^{230} \mathrm{Th}$ (Broecker and Thurber, 1965). Measurements of the relative abundance of ${ }^{230} \mathrm{Th},{ }^{238} \mathrm{U}$ and ${ }^{234} \mathrm{U}$ isotopes thus allows calculation of the age of the carbonate host because the decay rate is known, and most biogenic marine carbonates have little to no initial thorium. Mass spectrometric advances have enabled accurate determination of uranium and thorium isotopes in carbonates, establishing $\mathrm{U}-\mathrm{Th}$ dating as a tool to date carbonate as young as 3 years and as old as 600,000 years (Edwards et al., 2003). Recent developments in Multi-collector Inductively Coupled Plasma Mass Spectrometry (MC-ICP-MS) (Halliday et al., 1995; Albarède et al., 2004; McCulloch and Mortimer, 2008; Shen et al., 2008) have shown the possibility of obtaining good precision (1-5 years uncertainty) together with the advantage of reduced sample size, even for relatively modern, 'living' samples.

Most of these dating techniques have been applied to deep-sea 'gorgonian' corals (Grigg, 1974, 1977; Druffel et al., 1990; Risk et al., 2002; Roark et al., 2005, 2006; Sherwood et al., 2005). While they are the main contributors to deep-sea reef building, the age and growth characteristics of most deep-sea scleractinian corals are still largely unknown. The growth patterns of only few deep-sea scleractinian species have been studied. The first estimations of Duncan (1877) reported extension rates of 6.8 and $7.5 \mathrm{~mm} \mathrm{yr}^{-1}$ for specimens of the genus Lophelia that were attached to underwater transatlantic cables. More recently, Lophelia pertusa was found to have a minimum extension rate of $26 \mathrm{~mm} \mathrm{yr}^{-1}$ (Bell and Smith, 1999) while, Desmophyllum cristagalli shows a range of vertical extension rates from $0.5 \mathrm{~mm} \mathrm{yr}^{-1}$ to $2 \mathrm{~mm} \mathrm{yr}^{-1}$ (Cheng et al., 2000; Adkins et al., 2002, 2004). By using specimens maintained in aquaria, Orejas et al. (2007) found extension rates of $15-17 \mathrm{~mm} \mathrm{yr}^{-1}$ for $L$. pertusa, and between 3 and $18 \mathrm{~mm} \mathrm{yr}^{-1}$ for Madrepora oculata.

Among the dozen species of scleractinian corals living in the deep-sea, Enallopsammia rostrata (Pourtalès, 1878) is regarded as a major structure-forming species (Freiwald et al., 2004) and forms massive dendroid colonies, up to $1 \mathrm{~m}$ wide (Freiwald et al., 2004). It has a world-wide distribution, inhabiting depths from $\sim 200$ to $\sim 2000$ m (Cairns, 1984, 1995). Indeed, it contributes to reef formation in north eastern Atlantic waters (ICES, 2004), along the west Ireland continental shelf break, but also occurs in the tropical western and northwestern Atlantic (Packer et al., 2007; Ross and Nizinski, 2007). In the southwest Pacific, near New-Zealand, the flanks of the Chatham Rise and the Campbell Plateau are particularly rich in E. rostrata 
(Cairns, 1995; Probert et al., 1997; Burgess and Babcock, 2006). This species was also recently found in or adjacent to the Makapuu coral bed in the Hawaiian Islands (Parrish and Baco, 2007). Although, there have been few targeted surveys of deep-sea corals in the Pacific, there is a high likelihood that extensive reef areas will also be present (Freiwald et al., 2004). Despite its world-wide distribution and its important contribution to deep-reef building, to our knowledge only a single North Atlantic specimen has so far been analyzed with a combination of ${ }^{210} \mathrm{~Pb}$ and ${ }^{226} \mathrm{Ra}$ dating (Adkins et al., 2004) giving a growth rate of $0.07 \mathrm{~mm} \mathrm{yr}^{-1}$.

Here we present detailed ${ }^{234} \mathrm{U}^{2}{ }^{230} \mathrm{Th}$ series ages together with skeletal ultrastructure and main skeletal characteristics for five living samples of E. rostrata collected using the PISCES submersibles from the Equatorial Pacific. We measured ${ }^{232} \mathrm{Th}-{ }^{230} \mathrm{Th}-{ }^{229} \mathrm{Th}$ and ${ }^{238} \mathrm{U}-{ }^{234} \mathrm{U}-{ }^{233} \mathrm{U}$ in very small amounts of aragonite skeleton, giving age profiles for $E$. rostrata. The application of this method to colonies from different sites as well as the observation from thin sections of their axial skeletons offer the first data on longevity, growth pattern and mean growth rates in E. rostrata. In addition to providing the fundamental baseline for deepwater ecological studies, such information is critical in the development and assessment of this species as a useful paleoceanographic archive.

\section{MATERIALS AND METHODS}

\subsection{Field collection}

Living colonies of E. rostrata were collected in 2005 in the equatorial Pacific at Jarvis Island $\left(00^{\circ} 22.9 \mathrm{~S}, 160^{\circ}\right.$ $\left.1.5^{\prime} \mathrm{W}\right)$, Palmyra Atoll ( $\left.05^{\circ} 54.9 \mathrm{~N}, 162^{\circ} 08.5^{\prime} \mathrm{W}\right)$ and Kingman Reef $\left(06^{\circ} 26.0 \mathrm{~N}, 162^{\circ} 27.5^{\prime} \mathrm{W}\right)$ (Fig. 1) between 480 and $788 \mathrm{~m}$ depths using the PISCES IV research submersible. General information about the different E. rostrata colonies are given in Table 1. External tissues were removed aboard ship and intact skeletons returned to the laboratory.

These specimens of E. rostrata have been identified and recorded in the National Museum of Natural History in Washington under transaction number 2046035.

\subsection{Sample preparation}

Disks, 5-15 mm thick, were cut from basal cross-sections of all the samples. A cross-sectional disk was also cut from a branch of the colony P4-144-14. The disks were ultrasonicated in distilled water for up to $30 \mathrm{~min}$. During ultrasonication, the water was changed frequently until the water no longer turned cloudy.

\subsection{Laboratory methods}

\subsubsection{Thin section and organic matrix staining}

The cross-sectional disks of each colony were glued on microscope slides and polished to obtain $100 \mu \mathrm{m}$ slabs. The slabs were then decalcified in $1 \%$ acetic acid $(1 \mathrm{~h}$ 30 min immersion). After a gentle rinse with distilled water, the slabs were stained with a solution of $1 \%$ Toluidine blue for $10 \mathrm{~s}$ following the protocol of Marschal et al. (2004). To improve visualization of the organic matrix, slabs were stained several times.

Gray scale variability was measured using a digital image acquired through a stereographic microscope with the software image $\mathbf{J}$ (http://rsb.info.nih.gov/ij/). The radial gray scale variability was measured in three transects across the radius of two samples: P4-144-14, P4-147-1.

\subsection{2. ${ }^{232} T h-{ }^{230} T h-{ }^{229} T h$ and ${ }^{238} U{ }^{234}{ }^{23}{ }^{233} U$ measurements}

For uranium and thorium isotopic measurements, crosssection disks were sectioned with a computer-controlled micromill at $1.5 \mathrm{~mm}$ increments, with $70 \pm 15 \mathrm{mg}$ per sample being milled. The U-series isotopic dating was undertaken at the Research School of Earth Sciences, ANU following procedures developed and described by $\mathrm{McCul}-$ loch and Mortimer (2008). The coral carbonate samples were first covered with Milli-Q water with approximately five drop of concentrated $\mathrm{HNO}_{3}$ being added until the samples were fully dissolved. The samples were evaporated to a minimum volume, almost to dryness. All samples were totally spiked with a mixed ${ }^{229} \mathrm{Th}-{ }^{233} \mathrm{U}$ spike with 50 to $70 \mu \mathrm{l}$ of diluted ${ }^{229} \mathrm{Th}-{ }^{233} \mathrm{U}$ spike added to the sample. The spiked sample solutions were then evaporated almost to dryness and then redissolved in $2 \mathrm{M} \mathrm{HNO}_{3}$. The Th and $\mathrm{U}$ fractions were extracted and almost completely separated using a refined version of the procedure of Luo et al. (1997) and described in McCulloch and Mortimer (2008). Samples first passed through pre-filter column to remove any organic material and then through micro-ion-exchange columns of TRU spec resin eluted with a combination of $0.1 \mathrm{M} \mathrm{HCl}+0.02 \mathrm{M} \mathrm{HF}$ to collect the Th fraction, followed by $0.1 \mathrm{M} \mathrm{HCl}+0.3 \mathrm{M} \mathrm{HF}$ to collect the $\mathrm{U}$ fraction (Table 2). Chemical processing blanks were analytically insignificant even for modern samples, being typically $<10^{-16} \mathrm{~g}$ for ${ }^{230} \mathrm{Th}$ and were determined separately from the memory effects associated with the ICP-MS sample introduction system. The separated $\mathrm{U}$ and $\mathrm{Th}$ solutions were aspirated into the plasma of a Finnigan Neptune multi-collector ICP-MS system using an APEX desolvator with nebulizer operating with an uptake rate of $\sim 1.5 \mu \mathrm{s} \mathrm{s}^{-1}$ (McCulloch and Mortimer, 2008). A standardized set of plasma operating conditions was used which remained constant over each analytical session. An important issue is minimizing the residual blank memory that occasionally remains from previous samples. A regular cleaning procedure similar to that described by previous workers (Halliday et al., 1995; Hellstrom, 2003; Seth et al., 2003; Albarède et al., 2004) has been used. This consists of a combination of multi-step $2 \% \mathrm{HNO}_{3}, 0.05 \% \mathrm{HF}$, and $1 \%$ Triton surfactant. As demonstrated by McCulloch and Mortimer (2008) residuals ${ }^{229} \mathrm{Th}$ and ${ }^{230} \mathrm{Th}$ from previous samples as well as non-integer interferences can be reduced to acceptable levels with an appropriate cocktail of washing solutions together with close monitoring of the instrumental blank. For the youngest near modern samples, ${ }^{230} \mathrm{Th}$ measurements are corrected for residual instrument sample introduction memory (Table 3). ${ }^{230} \mathrm{Th} /{ }^{229} \mathrm{Th}$ ratios were measured with the high abundance RPQ in a peak jumping multi-collector mode with ${ }^{232} \mathrm{Th}$ being measured 


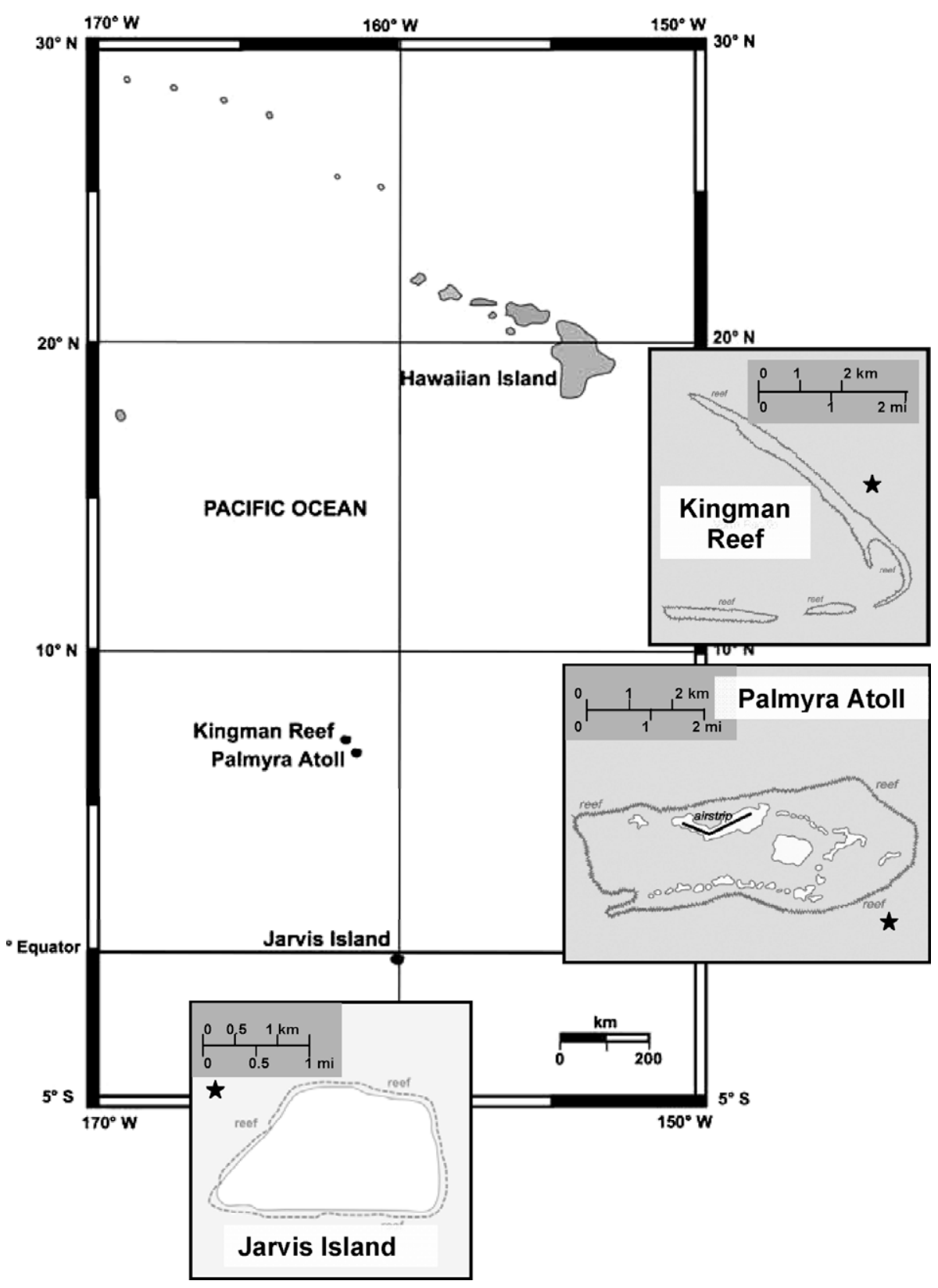

Fig. 1. Sampling areas. Map of the Equatorial Pacific with the three zones of sampling in the Line Islands: Kingman Reef, Palmyra Atoll and Jarvis Island. Black stars indicate the collecting points.

simultaneously in the Faraday cup mode. Uranium $\delta^{234} U$ compositions were measured using the central ion counter bracketed with the SRM 960 standard (McCulloch and Mortimer, 2008).

For each specimen, radial growth rates were calculated by dividing the oldest age in the U-series profile by the distance between the sample and the edge of the disk. Vertical growth rates were calculated by dividing the length of the colony by the oldest age. When the U-series profile showed different patterns, two radial growth rates were calculated (slower and faster) for the same sample. The growth rates are thus average values between the sampling points and the edge of the disk.

\section{RESULTS}

\subsection{General growth characteristics of $E$. rostrata}

The growth form of $E$. rostrata can be separated into two different morphotypes: (1) fan shaped colonies with only few branches, showing a dense and distinct trunk (Fig. 2); (2) colonies with a larger base and a more irregular and bushy structure (Fig. 3). For both types of E. rostrata, polyps are only located on one side of the colony (Fig. 3b). This may indicate that only one side of the colony is actively capturing particles, and oriented relative to the mean current direction. In the two different morphotypes, polyps 
Table 1

Summary of sample information, sampling zone, depth, morphotype (morph.) and maximal length (either width or high) and basal diameter (basal diam.) in $\mathrm{cm}$.

\begin{tabular}{|c|c|c|c|c|c|}
\hline $\begin{array}{l}\text { Sample } \\
\text { ID }\end{array}$ & Location & $\begin{array}{l}\text { Depth } \\
(\mathrm{m})\end{array}$ & Morph. & $\begin{array}{l}\text { Max } \\
\text { length }\end{array}$ & $\begin{array}{l}\text { Basal } \\
\text { diam. }\end{array}$ \\
\hline P4-146-3 & $\begin{array}{l}\text { Kingman Reef } \\
06^{\circ} 26.0 \mathrm{~N}, 162^{\circ} \\
27.5^{\prime} \mathrm{W}\end{array}$ & 480 & 1 & $\begin{array}{l}34.3 \\
\text { (width) }\end{array}$ & 3.1 \\
\hline P4-146-6 & & 788 & 1 & $\begin{array}{l}28.0 \\
\text { (width) }\end{array}$ & 2.9 \\
\hline P4-148-2 & $\begin{array}{l}\text { Palmyra Atoll } \\
05^{\circ} 50.784 \mathrm{~N}, \\
162^{\circ} 06.741^{\prime} \mathrm{W}\end{array}$ & 588 & 2 & $\begin{array}{l}41.0 \\
\text { (length) }\end{array}$ & 16.0 \\
\hline P4-147-1 & & 743 & 1 & $\begin{array}{l}38.0 \\
\text { (width) }\end{array}$ & 3.7 \\
\hline P4-144-14 & $\begin{array}{l}\text { Jarvis Island } \\
00^{\circ} 22.940 \mathrm{~S}, 160^{\circ} \\
1.457^{\prime} \mathrm{W}\end{array}$ & 532 & 2 & $\begin{array}{l}42.3 \\
\text { (length) }\end{array}$ & 15.5 \\
\hline
\end{tabular}

differ in their density, height and diameter. For type (1) (Fig. 2b), polyps are 4-7 mm wide and 1-3 mm high while for type (2) polyps are smaller, being only $2-3 \mathrm{~mm}$ wide, 2-8 $\mathrm{mm}$ high with a higher density, of $8-12$ polyps $\mathrm{cm}^{-2}$ (Fig. 3c).

\subsection{U-Series dating}

\subsubsection{Uranium and thorium concentrations}

${ }^{230} \mathrm{Th} /{ }^{232} \mathrm{Th},{ }^{234} \mathrm{U} /{ }^{238} \mathrm{U},{ }^{230} \mathrm{Th} /{ }^{238} \mathrm{U}$ activity ratios, uranium and thorium contents are presented in Table 3 . Uranium concentrations of these deep-sea coral samples are between 2.8 and $4.4 \mu \mathrm{g} \mathrm{g}^{-1}$. The average calculated initial $\left(\delta^{234} \mathrm{U} /{ }^{238} \mathrm{U}\right)_{0}$ ratio $146 \pm 1$ which is consistent at the $\pm 2 \sigma$ level of uncertainty with the seawater values determined by TIMS (Delanghe et al., 2002) or by MC-ICP-MS (Robinson et al., 2004; Montagna et al., 2006; McCulloch and Mortimer, 2008).

As it is common in deep-sea corals there are large variations in ${ }^{232} \mathrm{Th}$ contents, which varies between 0.03 and $0.9 \mathrm{ppb}$ but most typically has concentrations of less than $0.1 \mathrm{ppb}$. The highest ${ }^{232} \mathrm{Th}$ contents occur in coral P4-1482 , for which radial samples generally range from 0.12 to $0.8 \mathrm{ppb}$. These values are eight times higher than for the other samples. This clearly implies that ${ }^{232} \mathrm{Th}$ is derived from multiple sources, probably reflecting uptake from detrital components with a range of Th concentrations together with minor direct partitioning from seawater, which could account for the lowest 0.03 ppb concentrations. However with the exception of the near-modern outer margin samples or near living branch samples for which the ingrowth of radiogenic ${ }^{230} \mathrm{Th}$ is limited, the ${ }^{230} \mathrm{Th} /{ }^{232} \mathrm{Th}$ activity ratios are relatively high $\left(10^{2}\right.$ to $\left.10^{3}\right)$ (Table 3 ) and therefore the effects of initial, non-radiogenic ${ }^{230} \mathrm{Th}$ on the age is generally relatively minor. However for the near modern youngest sample (e.g., P4-144-14 branch A with an uncorrected age of 13 years) and those with $\left[{ }^{230} \mathrm{Th} /{ }^{232} \mathrm{Th}\right]$ activity ratios $<\sim 50$ its effect is significant relative to the analytical uncertainties and hence a correction
Table 2

Chemical procedure for the separation of Th and $\mathrm{U}$ from deep-sea coral carbonate samples.

\begin{tabular}{|c|c|c|c|}
\hline & Step & Details & Eluted \\
\hline \multirow[t]{4}{*}{$\begin{array}{l}\text { Pre-filtering } \\
\text { samples }^{\mathrm{a}}\end{array}$} & Resin & $\begin{array}{l}\text { Pre-filter resin, } \\
\sim 0.25 \mathrm{ml}\end{array}$ & \\
\hline & Cleaning & $\begin{array}{l}8 \times 1 \mathrm{ml} 0.05 \mathrm{M} \\
\mathrm{HCl}^{\mathrm{b}} \\
2 \times 1 \mathrm{ml} 0.02 \mathrm{M} \\
\mathrm{HNO}_{3} \\
3 \times 1 \mathrm{ml} 1 \mathrm{M} \\
\mathrm{HNO}_{3}\end{array}$ & \\
\hline & $\begin{array}{l}\text { Passing } \\
\text { samples }\end{array}$ & $\begin{array}{l}\text { In small aliquots } \\
(0.25 \mathrm{ml})\end{array}$ & \\
\hline & Washing & $1 \mathrm{ml} 1 \mathrm{M} \mathrm{HNO}_{3}$ & \\
\hline \multirow[t]{7}{*}{$\begin{array}{l}\text { Separation U } \\
\text { and } \mathrm{Th}^{\mathrm{c}}\end{array}$} & Resin & $\begin{array}{l}\text { Pre-filter resin, } \\
\sim 0.25 \mathrm{ml} \\
\text { TRU. Spec resin, } \\
\sim 0.4 \mathrm{ml}\end{array}$ & \\
\hline & Cleaning & $\begin{array}{l}10 \times 1 \mathrm{ml} 0.05 \mathrm{M} \\
\mathrm{HCl} \\
8 \times 1 \mathrm{ml} 0.1 \mathrm{M} \\
\mathrm{HCl}-0.1 \mathrm{M} \mathrm{HF} \\
6 \times 1 \mathrm{ml} 0.1 \mathrm{M} \\
\mathrm{HCl}-0.3 \mathrm{M} \mathrm{HF}\end{array}$ & \\
\hline & Conditioning & $\begin{array}{l}3 \times 0.4 \mathrm{ml} 1 \mathrm{~N} \\
\mathrm{HNO}_{3}\end{array}$ & \\
\hline & $\begin{array}{l}\text { Loading } \\
\text { samples }\end{array}$ & $\begin{array}{l}1.5-2 \mathrm{ml} 2 \mathrm{M} \\
\mathrm{HNO}_{3}\end{array}$ & \\
\hline & Washing & $2.75 \mathrm{ml} 2 \mathrm{M} \mathrm{HNO}_{3}$ & $\begin{array}{l}\text { All major } \\
\text { elements }\end{array}$ \\
\hline & & $\begin{array}{l}0.1 \mathrm{ml} 0.1 \mathrm{M} \mathrm{HCl} / \\
0.02 \mathrm{M} \mathrm{HF}\end{array}$ & $\begin{array}{l}\text { Rare earth } \\
\text { elements }\end{array}$ \\
\hline & Collection & $\begin{array}{l}0.8 \mathrm{ml} 0.1 \mathrm{M} \mathrm{HCl} / \\
0.02 \mathrm{M} \mathrm{HF} \\
0.8 \mathrm{ml} 0.1 \mathrm{M} \mathrm{HCl} / \\
0.3 \mathrm{M} \mathrm{HF}\end{array}$ & $\begin{array}{l}\text { Thorium } \\
\text { Uranium }\end{array}$ \\
\hline
\end{tabular}

a Passage through the pre-filter columns is used to remove organic material.

${ }^{b}$ The authors passed eight times $1 \mathrm{ml}$ of $0.05 \mathrm{M} \mathrm{HCl}$ through the pre-filter column.

${ }^{\mathrm{c}}$ Samples passed through pre-filter resin and TRU. Spec resin to separate $\mathrm{U}$ and $\mathrm{Th}$ fractions.

procedure similar to that described by McCulloch and Mortimer (2008) as described below was applied.

3.2.2. ${ }^{234} U-{ }^{230}$ Th ages

${ }^{234} \mathrm{U}-{ }^{230} \mathrm{Th}$ ages were calculated using the half-lives adopted by Cheng et al. (2000) and corrections for nonradiogenic ${ }^{23 \mathrm{O}} \mathrm{Th}$ following a similar approach as described by McCulloch and Mortimer (2008). In this study, the correction applied to the U-series equation Cheng et al. (2000) for a non-radiogenic component of ${ }^{230} \mathrm{Th}$ is given by the following relationship where ratios are expressed as activities:

$\left[{ }^{230} \mathrm{Th}_{\mathrm{rad}} /{ }^{238} \mathrm{U}\right]=\left[{ }^{230} \mathrm{Th}_{\text {meas }} /{ }^{238} \mathrm{U}\right]-\left[{ }^{232} \mathrm{Th} /{ }^{238} \mathrm{U}\right]\left[{ }^{230} \mathrm{Th}\right.$ nr $/$ $\left.{ }^{232} \mathrm{Th}\right] \exp \left[-\lambda_{230} T\right]$, where ${ }^{230} \mathrm{Th}_{\text {rad }}$ corresponds to the radio- 
Table 3

$\mathrm{U}$ and $\mathrm{Th}$ isotopic composition and ${ }^{230} \mathrm{Th}$ ages of modern E. rostrata. ${ }^{230} \mathrm{Th} /{ }^{238} \mathrm{U}$ and ${ }^{230} \mathrm{Th} /{ }^{232} \mathrm{Th}$ are activity ratios.

\begin{tabular}{|c|c|c|c|c|c|c|c|c|c|c|}
\hline Sample ID & $\begin{array}{l}\text { Distance } \\
(\mathrm{mm})^{*}\end{array}$ & $\begin{array}{l}\mathrm{U} \\
(\mathrm{ppm})\end{array}$ & $\begin{array}{l}{ }^{232} \mathrm{Th} \\
(\mathrm{ppb})\end{array}$ & $\begin{array}{l}\delta^{234} \mathrm{U} \\
\text { (measured) }\end{array}$ & ${ }^{230} \mathrm{Th} /{ }^{238} \mathrm{U}$ & ${ }^{230} \mathrm{Th} /{ }^{232} \mathrm{Th}$ & $\begin{array}{l}\text { Age } \\
{(\text { year })^{a}}^{2}\end{array}$ & $\begin{array}{l}\delta^{234} U \\
\text { (initial) }\end{array}$ & $\begin{array}{l}\text { Corrected age } \\
\text { (years) })^{\mathrm{b}}\end{array}$ & $\begin{array}{l}\text { Corrected age } \\
\text { (years) }^{c}\end{array}$ \\
\hline P4-146-3 & 1.5 & 4.23 & 0.17 & $145.1 \pm 1.9$ & $0.00150 \pm 0.00002$ & 115.3 & $142 \pm 2$ & $145.2 \pm 1.9$ & $141 \pm 2$ & $136 \pm 5$ \\
\hline \multirow{4}{*}{ Branch } & 5 & 4.15 & 0.04 & $146.3 \pm 2.1$ & $0.00429 \pm 0.00006$ & 1333.1 & $408 \pm 5$ & $146.5 \pm 2.1$ & $408 \pm 5$ & $406 \pm 6$ \\
\hline & 9 & 3.50 & 0.04 & $145.2 \pm 1.2$ & $0.00638 \pm 0.00007$ & 1706.9 & $607 \pm 7$ & $145.5 \pm 1.1$ & $607 \pm 7$ & $605 \pm 7$ \\
\hline & 13 & 3.11 & 0.03 & $146.2 \pm 1.9$ & $0.00608 \pm 0.00006$ & 1702.5 & $578 \pm 5$ & $146.4 \pm 1.8$ & $578 \pm 5$ & $576 \pm 6$ \\
\hline & 19 & 4.13 & 0.03 & $147.3 \pm 2.2$ & $0.00338 \pm 0.00003$ & 1273.4 & $321 \pm 3$ & $147.4 \pm 2.3$ & $321 \pm 3$ & $320 \pm 3$ \\
\hline P4-146-6 & 0 & 4.84 & 0.22 & $147.1 \pm 1.4$ & $0.00225 \pm 0.00003$ & 151.3 & $214 \pm 3$ & $147.2 \pm 1.3$ & $212 \pm 4$ & $207 \pm 7$ \\
\hline \multirow{4}{*}{ Base } & 3 & 4.19 & 0.14 & $146.0 \pm 1.5$ & $0.00199 \pm 0.00005$ & 190.3 & $189 \pm 5$ & $146.1 \pm 1.5$ & $188 \pm 5$ & $184 \pm 7$ \\
\hline & 6 & 3.31 & 0.07 & $145.4 \pm 1.5$ & $0.00273 \pm 0.00006$ & 382.4 & $259 \pm 6$ & $145.6 \pm 1.4$ & $258 \pm 6$ & $256 \pm 8$ \\
\hline & 12 & 3.22 & 0.06 & $146.6 \pm 1.0$ & $0.00226 \pm 0.00006$ & 360.1 & $214 \pm 5$ & $146.7 \pm 1.0$ & $214 \pm 5$ & $211 \pm 6$ \\
\hline & 16.5 & 4.21 & 0.10 & $146.5 \pm 1.5$ & $0.00099 \pm 0.00003$ & 129.3 & $94 \pm 3$ & $146.5 \pm 1.5$ & $93 \pm 3$ & $90 \pm 5$ \\
\hline P4-148-2 & 1.5 & 3.19 & 0.77 & $144.4 \pm 1.4$ & $0.00176 \pm 0.00004$ & 23.1 & $168 \pm 4$ & $144.5 \pm 1.3$ & $160 \pm 8$ & $131 \pm 23$ \\
\hline \multirow{10}{*}{ Base } & 3 & 2.78 & 0.40 & $150.4 \pm 2.9$ & $0.00264 \pm 0.00008$ & 59.1 & $250 \pm 8$ & $150.5 \pm 2.8$ & $246 \pm 10$ & $229 \pm 18$ \\
\hline & 4.5 & 2.71 & 0.31 & $145.1 \pm 1.9$ & $0.00302 \pm 0.00006$ & 82.5 & $287 \pm 6$ & $145.2 \pm 1.8$ & $284 \pm 7$ & $270 \pm 14$ \\
\hline & 6 & 2.66 & 0.52 & $145.1 \pm 1.1$ & $0.00358 \pm 0.00008$ & 57.7 & $340 \pm 8$ & $145.3 \pm 1.0$ & $334 \pm 11$ & $311 \pm 22$ \\
\hline & 9 & 2.56 & 0.84 & $145.6 \pm 2.0$ & $0.00259 \pm 0.00007$ & 25.3 & $246 \pm 6$ & $145.8 \pm 2.0$ & $236 \pm 11$ & $198 \pm 31$ \\
\hline & 12 & 2.67 & 0.53 & $146.5 \pm 1.8$ & $0.00286 \pm 0.00006$ & 45.9 & $272 \pm 6$ & $146.6 \pm 1.8$ & $266 \pm 9$ & $242 \pm 21$ \\
\hline & 15 & 2.59 & 0.62 & $146.2 \pm 1.9$ & $0.00296 \pm 0.00011$ & 39.7 & $281 \pm 10$ & $146.3 \pm 1.8$ & $274 \pm 13$ & $246 \pm 28$ \\
\hline & 18 & 2.49 & 0.48 & $145.3 \pm 3.4$ & $0.00199 \pm 0.00014$ & 33.6 & $189 \pm 13$ & $145.4 \pm 3.2$ & $183 \pm 16$ & $161 \pm 27$ \\
\hline & 19.5 & 2.38 & 0.18 & $144.4 \pm 2.4$ & $0.00200 \pm 0.00007$ & 84.2 & $190 \pm 7$ & $144.4 \pm 2.4$ & $188 \pm 8$ & $179 \pm 12$ \\
\hline & 21 & 3.16 & 0.12 & $146.5 \pm 1.7$ & $0.00332 \pm 0.00008$ & 275.7 & $315 \pm 7$ & $146.6 \pm 1.6$ & $314 \pm 8$ & $309 \pm 10$ \\
\hline & 24 & 4.11 & 0.99 & $145.9 \pm 1.3$ & $0.00380 \pm 0.00007$ & 48.5 & $362 \pm 6$ & $146.1 \pm 1.3$ & $354 \pm 10$ & $323 \pm 26$ \\
\hline P4-147-1 & 0 & 3.73 & 0.23 & $146.4 \pm 1.1$ & $0.00087 \pm 0.00004$ & 46.3 & $82 \pm 4$ & $146.5 \pm 1$ & $81 \pm 5$ & $73 \pm 8$ \\
\hline \multirow[t]{11}{*}{ Base } & 1.5 & 3.56 & 0.06 & $148.1 \pm 0.8$ & $0.00091 \pm 0.00003$ & 173.9 & $86 \pm 2$ & $148.1 \pm 0.8$ & $85 \pm 3$ & $83 \pm 4$ \\
\hline & 4.5 & 2.98 & 0.05 & $146.6 \pm 1.8$ & $0.00109 \pm 0.00004$ & 205.6 & $103 \pm 4$ & $146.7 \pm 1.7$ & $103 \pm 4$ & $101 \pm 5$ \\
\hline & 7.5 & 2.89 & 0.07 & $144.1 \pm 2.2$ & $0.00150 \pm 0.00007$ & 199.3 & $143 \pm 6$ & $144.1 \pm 2.2$ & $142 \pm 7$ & $139 \pm 8$ \\
\hline & 9 & 2.84 & 0.14 & $144.3 \pm 3.3$ & $0.00143 \pm 0.00006$ & 90.6 & $136 \pm 5$ & $144.3 \pm 3.2$ & $135 \pm 6$ & $129 \pm 9$ \\
\hline & 10.5 & 3.18 & 0.14 & $146.3 \pm 1.4$ & $0.00179 \pm 0.00004$ & 128.1 & $170 \pm 4$ & $146.3 \pm 1.3$ & $168 \pm 4$ & $163 \pm 7$ \\
\hline & 12 & 2.85 & 0.16 & $145.2 \pm 1.3$ & $0.00168 \pm 0.00007$ & 99.4 & $160 \pm 6$ & $145.2 \pm 1.3$ & $158 \pm 7$ & $152 \pm 10$ \\
\hline & 15 & 2.54 & 0.09 & $144.4 \pm 2.0$ & $0.00225 \pm 0.00006$ & 204.3 & $214 \pm 5$ & $144.5 \pm 1.9$ & $213 \pm 6$ & $209 \pm 8$ \\
\hline & 18 & 2.88 & 0.07 & $145.2 \pm 2.6$ & $0.00221 \pm 0.00008$ & 291.1 & $210 \pm 8$ & $145.3 \pm 2.6$ & $209 \pm 8$ & $206 \pm 9$ \\
\hline & 21 & 3.96 & 0.06 & $144.3 \pm 1.5$ & $0.00126 \pm 0.00005$ & 273.5 & $120 \pm 5$ & $144.4 \pm 1.4$ & $120 \pm 5$ & $118 \pm 6$ \\
\hline & 22.5 & 3.99 & 0.12 & $145.1 \pm 2.5$ & $0.00082 \pm 0.00004$ & 94.0 & $78 \pm 4$ & $145.1 \pm 2.5$ & $77 \pm 4$ & $74 \pm 6$ \\
\hline & 24 & 4.22 & 0.21 & $144.3 \pm 2.0$ & $0.00061 \pm 0.00004$ & 41.8 & $58 \pm 4$ & $144.3 \pm 2$ & $57 \pm 5$ & $51 \pm 7$ \\
\hline P4-144-14 & 2 & 4.41 & 0.03 & $145.8 \pm 1.0$ & $0.00027 \pm 0.00001$ & 155.3 & $26 \pm 1$ & $145.8 \pm 1.0$ & $26 \pm 1$ & $25 \pm 1$ \\
\hline \multirow[t]{3}{*}{ Base } & 5 & 2.79 & 0.04 & $145.8 \pm 0.9$ & $0.00126 \pm 0.00004$ & 309.2 & $119 \pm 5$ & $145.8 \pm 0.9$ & $119 \pm 5$ & $117 \pm 5$ \\
\hline & 9 & 2.37 & 0.03 & $144.9 \pm 1.1$ & $0.00114 \pm 0.00003$ & 250.4 & $108 \pm 3$ & $144.9 \pm 1.0$ & $108 \pm 3$ & $106 \pm 4$ \\
\hline & 13 & 2.79 & 0.14 & $145.9 \pm 1.1$ & $0.00238 \pm 0.00004$ & 149.0 & $226 \pm 4$ & $146.0 \pm 1.1$ & $224 \pm 5$ & $218 \pm 8$ \\
\hline \multirow[t]{3}{*}{ Branch } & A 0.35 & 3.08 & 0.22 & $146.1 \pm 1.1$ & $0.00013 \pm 0.00001$ & 9.1 & $13 \pm 1$ & $146.1 \pm 1.1$ & $11 \pm 2$ & $6 \pm 5$ \\
\hline & В 0.8 & 1.86 & 0.07 & $144.9 \pm 1.4$ & $0.00034 \pm 0.00002$ & 32.8 & $32 \pm 2$ & $144.9 \pm 1.4$ & $31 \pm 2$ & $27 \pm 4$ \\
\hline & C 1.1 & 2.97 & 0.19 & $147.8 \pm 0.7$ & $0.00090 \pm 0.00002$ & 45.5 & $85 \pm 2$ & $147.8 \pm 0.7$ & $83 \pm 3$ & $76 \pm 6$ \\
\hline
\end{tabular}

Uranium-series data of modern E. rostrata used in this study. Half-lives of ${ }^{234} \mathrm{U}$ and ${ }^{230} \mathrm{Th}$ used in the calculations are $234.250 \pm 490$ years and $75.690 \pm 230$ years, respectively (Cheng et al., 2000$)$. $\lambda_{238}$ is $1.551 \times 10^{-10}$ per

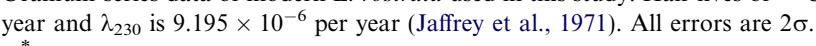

Distance from the edge of the transect in $\mathrm{mm}$.

Age after correction for instrument sample introduction memory.

${ }^{b}$ Age after correction for memory and $\left.{ }^{230} \mathrm{Th} /{ }^{232} \mathrm{Th}\right]$ non-radiogenic detrital component using $\left[{ }^{230} \mathrm{Th} \mathrm{nr}^{232} \mathrm{Th}\right]=1$.

${ }^{c}$ Age after correction for memory and $\left.{ }^{230} \mathrm{Th} /{ }^{232} \mathrm{Th}\right]$ non-radiogenic detrital component using $\left[{ }^{230} \mathrm{Th}_{\mathrm{nr}} /{ }^{232} \mathrm{Th}\right]=5$. 

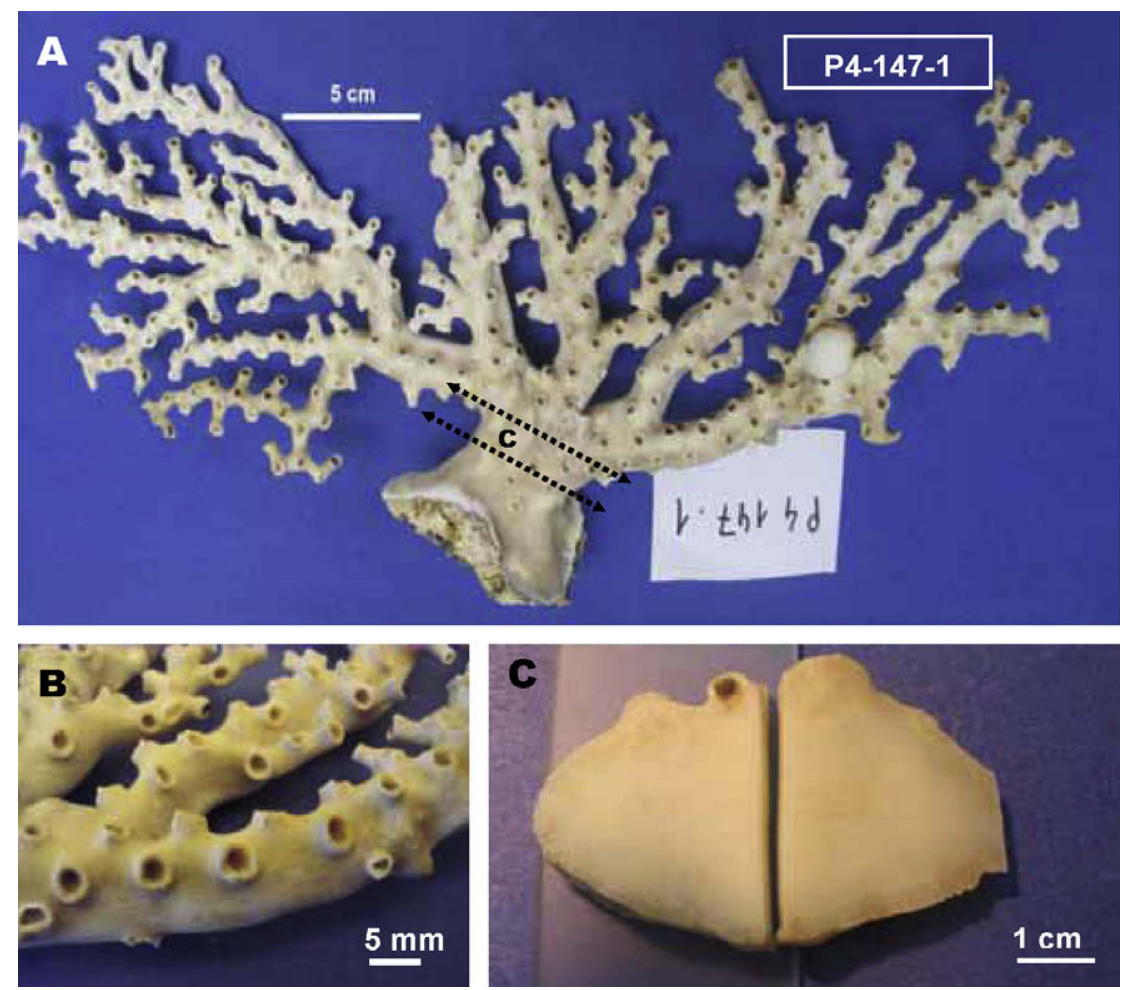

Fig. 2. (A) Photograph of E. rostrata sample P4-147-1 (collected around Palmyra Atoll at $743 \mathrm{~m}$ depth). This colony of $38 \mathrm{~cm}$ wide and $12.4 \mathrm{~cm}$ length presents distinct branches attached to a dense and distinct trunk, which diameter is $3.7 \mathrm{~cm}$. We called this type of morphology, morphotype 1. Black dotted lines show where the sampling disk C was cut. (B) Polyps of sample P4-147-1, showing diameters include between 4 and $7 \mathrm{~mm}$. Polyp density is not higher than 2-3 polyps $\mathrm{cm}^{-2}$. (C) Photograph of the sampling disk.
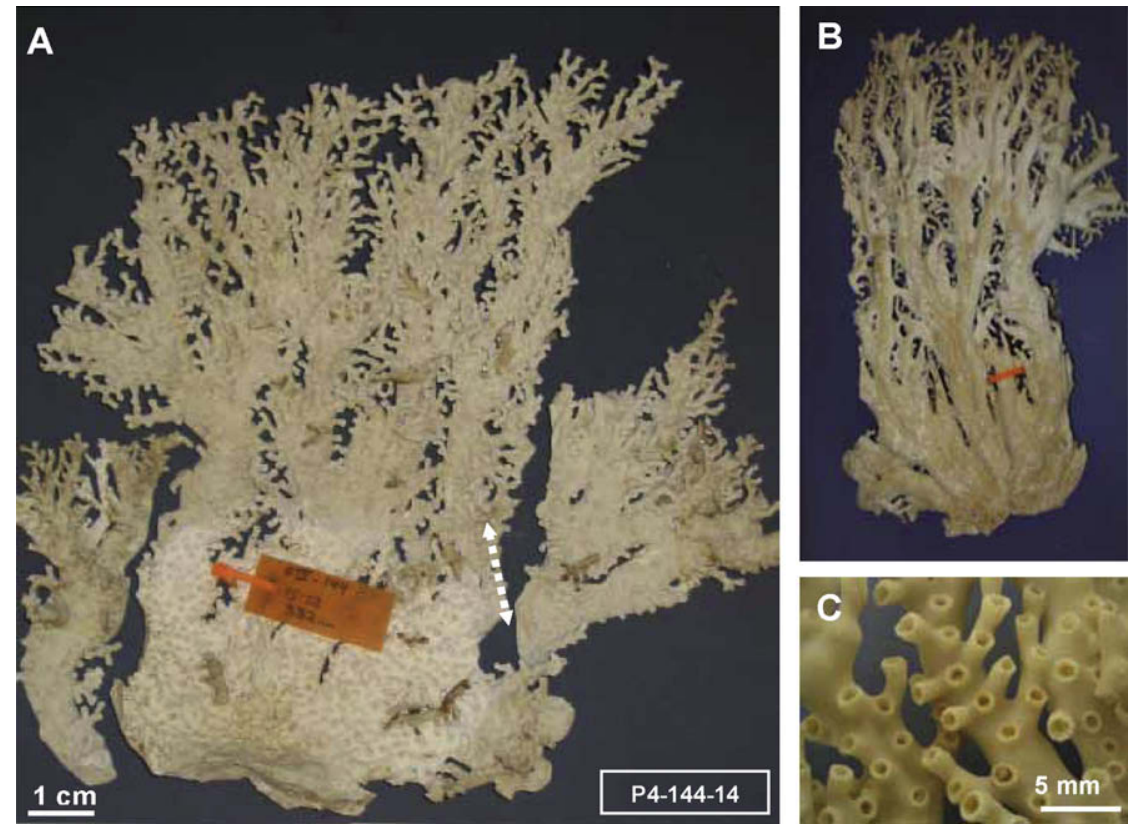

Fig. 3. (A) Photograph of E. rostrata sample P4-144-14 (collected around Jarvis Island at $532 \mathrm{~m}$ depth). This colony of $42 \mathrm{~cm}$ length presents a large base $(15.5 \mathrm{~cm})$, an irregular bushy structure. We called this type of morphology, morphotype 2 . White dotted line shows where the sampling disks were taken. (B) Photograph of sample P4-144-14's back, showing the absence of polyps on this face. (C) Polyps of sample P4144-14 (diameter: $4-7 \mathrm{~mm}$; height: $2-8 \mathrm{~mm}$ ). Polyp density is $8-12$ polyps $\mathrm{cm}^{-2}$. 
genic ${ }^{230} \mathrm{Th},{ }^{230} \mathrm{Th}_{\text {meas }}$ corresponds to the ${ }^{230} \mathrm{Th}$ measured in the sample and ${ }^{230} \mathrm{Th}_{\mathrm{nr}}$ to the non-radiogenic ${ }^{230} \mathrm{Th}, T$ is the age in years and $\lambda_{230}$ is the decay constant for ${ }^{230} \mathrm{Th}$.

For samples with $\left[{ }^{230} \mathrm{Th} /{ }^{232} \mathrm{Th}\right]<\sim 50$ it is important to estimate the contribution from inherited non-radiogenic ${ }^{230} \mathrm{Th}$ components as these give older age offsets that can be significant relative to analytical uncertainties. To assess the variability in the inherited $\left[{ }^{230} \mathrm{Th}_{\mathrm{nr}} /{ }^{232} \mathrm{Th}\right]$, McCulloch and Mortimer (2008) calculated the value of the non-radiogenic ratio of $\left[{ }^{230} \mathrm{Th}_{\mathrm{nr}} /{ }^{232} \mathrm{Th}\right]$ required to account for the difference between the true age and the actual age measured in the coral (after blank correction). In the study of McCulloch and Mortimer (2008), this was possible due to the well developed and clearly understood annual banding in shallow-water corals validated by diagnostic river flood events. The calculated $\left[{ }^{230} \mathrm{Th}_{\mathrm{nr}} /{ }^{232} \mathrm{Th}\right.$ ] ratios ranged from 4.8 to 0.22 and did not correlate with concentration of ${ }^{232} \mathrm{Th}$, indicating variable non-radiogenic components. In the current study, it was not possible to follow the same approach, as there are no independent constraints on the deep-sea coral ages, except for the outmost portions that are still actively growing. From the highest $(42.3 \mathrm{~cm})$ fastest growing colony P4-144-14 the actively growing tip from a branch (A 0.35) was therefore sampled. Based on the mean extension rate of this branch (which is insensitive to the ${ }^{230} \mathrm{Th}_{\mathrm{nr}}$ see below) a mean age for this outermost sample of $\sim 5 \pm 3$ years was estimated. From the measured $\left[{ }^{230} \mathrm{Th} /{ }^{232} \mathrm{Th}\right]$ ratio of 9.1 , this implies a $\left[{ }^{230} \mathrm{Th}_{\mathrm{nr}} /{ }^{232} \mathrm{Th}\right]$ of $4 \pm 1$. Therefore a range of ${ }^{230} \mathrm{Th}_{\mathrm{rad}}$ are assumed with $\left[{ }^{230} \mathrm{Th}\right.$ rr $\left./ 232 \mathrm{Th}\right]=1$ but also $\left[{ }^{230} \mathrm{Th}_{\mathrm{nr}}{ }^{232} \mathrm{Th}\right]=5$. The effect of inherited ${ }^{230} \mathrm{Th}_{\mathrm{nr}}$ on the ages using these two different ratios is shown in Table 3. There is little difference except for samples P4-144-14 (points B and C) and sample P4-148-2, with $\left[{ }^{230} \mathrm{Th} /{ }^{232} \mathrm{Th}\right]$ activity ratios less than 50 . Thus for the majority of the samples, the age uncertainty, introduced from ${ }^{230} \mathrm{Th}_{\mathrm{nr}}$ ranges from 2 to 10 years maximum. In the text, ages are given based on the most conservative estimate of $\left[{ }^{230} \mathrm{Th}_{\mathrm{nr}} /{ }^{232} \mathrm{Th}\right]=5$.

$\mathrm{Th} / \mathrm{U}$-ages calculated in the basal disk for the different samples of E. rostrata are presented in Tables 3 and 4. Life spans for the five colonies range from $209 \pm 8 \mathrm{yr}$ to $605 \pm 7$ yr for P4-147-1 and P4-146-3, respectively. Th/U- ages calculated in the branch of the sample P4-144-14 (Fig. $5 \mathrm{~b}$ and c) are $76 \pm 6 \mathrm{yr}$ and $6 \pm 5 \mathrm{yr}$ and for the inner and outer parts of the branch disk, respectively (Table 3).

\subsubsection{Growth rates}

Th/U-ages of sample P4-147-1 range from $51 \pm 7$ years at the outer margin to $209 \pm 8$ years old at the center (Fig. 4a). The growth of sample P4-147-1 is not symmetrical, with the oldest age being slightly off-center from the middle of the disk. This sample shows a clear preferential growth axis (Fig. 6a). Along the major growth axis, the estimated radial growth rate is $0.072 \mathrm{~mm} \mathrm{yr}^{-1}$ while it is almost two times slower on the other side $\left(0.043 \mathrm{~mm} \mathrm{yr}^{-1}\right)$ (Fig. 4a, Table 4). The pattern of U-series dating profile for sample P4-146-3 (Fig. 4b) is similar to that observed in sample $\mathrm{P} 4-147-1$. The inner $\mathrm{Th} / \mathrm{U}$-age along the radial transect is $605 \pm 7$ years old, and $136 \pm 5$ years at the outer edge. Along the major growth axis, this sample shows a radial growth rate of $0.017 \mathrm{~mm} \mathrm{yr}^{-1}$ and of $0.012 \mathrm{~mm} \mathrm{yr}^{-1}$ on the opposite side (Fig. 4b, Table 4). The sample P4-146-6 also shows a clear preferential growth axis, showing a rate of $0.041 \mathrm{~mm} \mathrm{yr}^{-1}$ and a slower growth axis of $0.023 \mathrm{~mm} \mathrm{yr}^{-1}$ on the opposite side (Fig. 4c, Table 4). $\mathrm{Th} / \mathrm{U}$-ages of sample P4-146-6 range from $76 \pm 6$ years at the outer margin to $256 \pm 8$ years old at the center (Fig. 4c).

For samples P4-144-14 and P4-148-2 (Fig. 4d and e), both of morphotype 2, differential growth patterns can also be deduced from their U-series dating profiles. In P4-14414 , Th/U-ages ranging from $25 \pm 1$ years at the polyp side of the disk to $218 \pm 8$ years old at the opposite outer side, indicating a radial growth rate of $0.057 \mathrm{~mm} \mathrm{yr}^{-1}$ along the preferential growth axis (Fig. 4d, Table 4). For sample P4-148-2, Th/U-ages fluctuate between $131 \pm 22$ years and $325 \pm 25$ years (Fig. 4e). The U-sampling transect crossed three different starting growth points, located at 6, 15 and $24 \mathrm{~mm}$ from the polyp side of the disk and do not give a representative radial growth rate (Fig. 4e, Table 4).

On average the highest radial growth rate of E. rostrata is about $0.047 \pm 0.014 \mathrm{~mm} \mathrm{yr}^{-1}$.

Vertical extension rates for the five different E. rostrata specimens range from 0.6 to $1.9 \mathrm{~mm} \mathrm{yr}^{-1}$ (Table 4).

Table 4

Summary of sample information: location, depth (m), maximum length (max. length) and basal diameter in cm (basal diam.) age (in years) and growth rates (radial and vertical growth rates). For samples P4-146-3, P4-146-6 and P4-147-1, the U-age profiles allowed us to calculate radial growth rates (rad. growth rates) (slowest and fastest) and vertical extension rates (vert. ext. rates) expressed in $\mathrm{mm} \mathrm{yr}^{-1}$.

\begin{tabular}{|c|c|c|c|c|c|c|c|c|c|}
\hline \multirow[t]{2}{*}{ Sample ID } & \multirow[t]{2}{*}{ Location } & \multirow[t]{2}{*}{ Depth } & \multirow[t]{2}{*}{ Morph. } & \multirow[t]{2}{*}{ Max. length } & \multirow[t]{2}{*}{ Basal diam. } & \multirow[t]{2}{*}{ Age } & \multicolumn{2}{|c|}{ Rad. growth rates } & \multirow[t]{2}{*}{ Vert. ext. rates } \\
\hline & & & & & & & Lowest & Fastest & \\
\hline P4-146-3 & $\begin{array}{l}\text { Kingman Reef } \\
06^{\circ} 26.0 \mathrm{~N}, 162^{\circ} 27.5^{\prime} \mathrm{W}\end{array}$ & 480 & 1 & 34.3 (width) & 3.1 & $605 \pm 7$ & 0.012 & 0.017 & 0.6 \\
\hline P4-146-6 & & 788 & 1 & 28.0 (width) & 2.9 & $256 \pm 8$ & 0.023 & 0.041 & 1.1 \\
\hline P4-148-2 & $\begin{array}{l}\text { Palmyra Atoll } \\
05^{\circ} 50.784 \mathrm{~N}, 162^{\circ} 06.741^{\prime} \mathrm{W}\end{array}$ & 588 & 2 & 41.0 (length) & 16.0 & $323 \pm 26$ & - & - & 1.3 \\
\hline P4-147-1 & & 743 & 1 & 38.0 (width) & 3.7 & $209 \pm 8$ & 0.043 & 0.072 & 1.8 \\
\hline P4-144-14 & $\begin{array}{l}\text { Jarvis Island } \\
00^{\circ} 22.940 \mathrm{~S}, 160^{\circ} 1.457^{\prime} \mathrm{W}\end{array}$ & 532 & 2 & 42.3 (length) & 15.5 & $218 \pm 8$ & & 0.057 & 1.9 \\
\hline
\end{tabular}



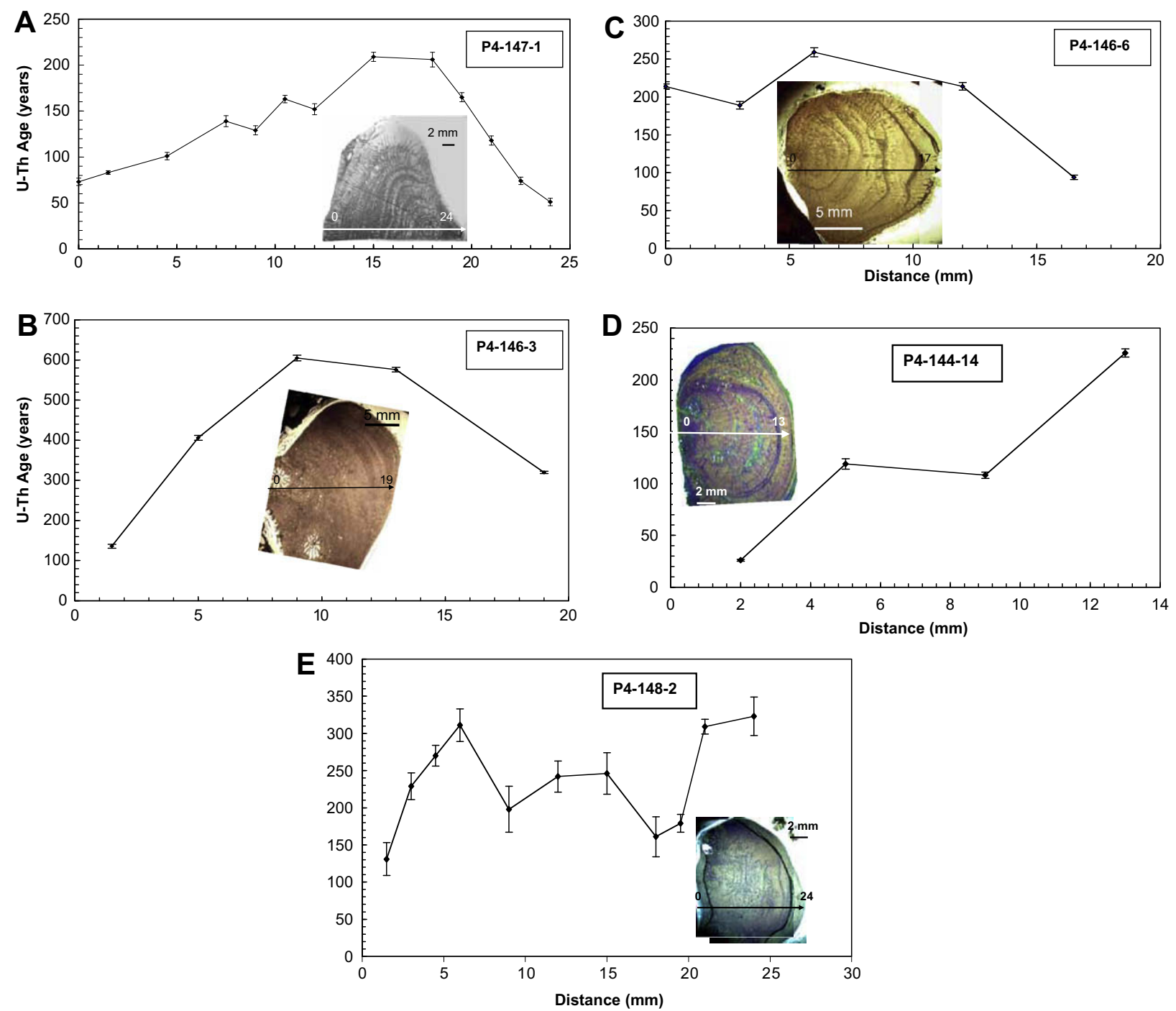

Fig. 4. U-Th age measurements from the radial transect across the entire trunk (A) P4-147-1, (B) P4-146-3 (C) P4-146-6 (D) P4-144-14 (E) P4148-2. U-Th sampling tracks are represented by some black or white arrows on the photographs of the sample disk thin sections.
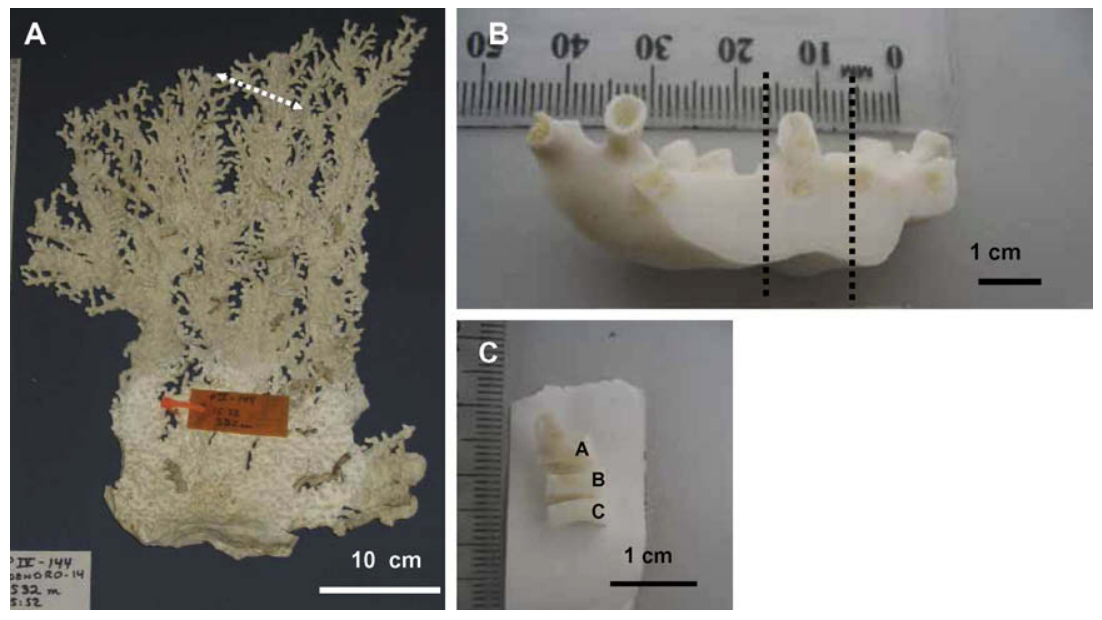

Fig. 5. (A) Photograph of E. rostrata sample P4-144-14. White dotted line show where the sampling disk was cut in the branches. (B) Photograph of the sampling disk made in the branch. Black dotted lines delimit where the U-Th measurements were made. (C) Photograph of the three skeleton pieces analyzed to determine $\mathrm{U}-\mathrm{Th}$ ages. 


\section{A}
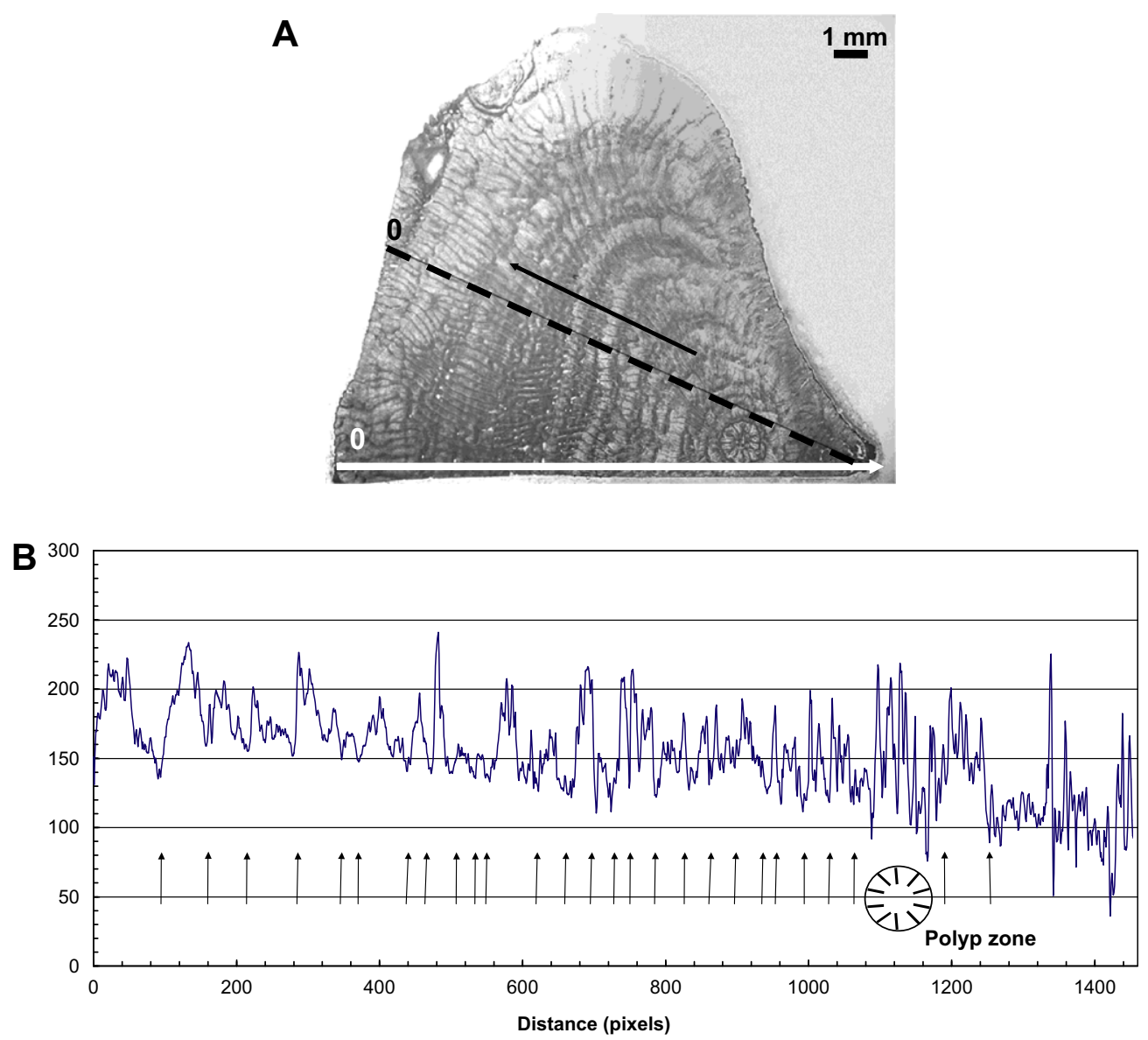

Fig. 6. (A) Microscopy image with transmitted light of the thin section made in the trunk of sample P4-147-1. U-Th sampling track is represented by a white line. The organic matrix of the skeleton has been stained with Toluidine blue to make appear the growth rings. (B) Gray scale variation across three radial lines, only one has been represented on the photograph by a black dotted line. Black arrows indicate the density bands. For each radial line, there are $<24-27$ bands. This specimen is 209 years old. These gray scale data suggest only one band about every 6 years for this sample.

\subsection{Growth bands}

Thin sections from the base of samples P4-147-1 and P4144-14 have been stained with Toluidine blue to highlight the skeletal organic matrix. In both samples, the staining revealed growth bands of variable thickness (Figs. 6 and 7a). The distances between growth rings are very irregular, especially for sample P4-144-14 (Fig 7a and b). Due to the discontinuity of these bands, cross-sections can differ from one another, which requires a growth band count along several closed transects: i.e., to confirm circuitry of the rings. With the software image $\mathrm{J}$, we measured the radial gray scale variability in the region where we sampled for U-series dating. For sample P4-147-1 (Fig. 6a and b), the three separate transects across the coral's radius show consistent results of 24-27 growth bands. Given the $0.072 \mathrm{~mm} \mathrm{yr}^{-1}$ highest radial growth rate calculated using $\mathrm{U}-\mathrm{Th}$ ages and a 12 $\mathrm{mm}$ radial distance in this part of the section, the gray scale data suggest only one band about every 6 years for this sample. The other thin section from the base of sample P4-144-14 (Fig. 7a and b) reveals a total of 16-18 growth bands. From its diameter of $13.8 \mathrm{~mm}$ and growth rate of $0.057 \mathrm{~mm} \mathrm{yr}^{-1}$, this sample shows that a band formed on average about every 15 years.

\section{DISCUSSION}

This study, using U-series dating technique provides the first quantitative estimates of growth rates and longevity for specimens of E. rostrata, collected from a range of depths and localities in the Equatorial Pacific Ocean.

With concentrations ranging from 2.6 to $4.9 \mu \mathrm{g} \mathrm{g}^{-1}$, carbonate skeletons of $E$. rostrata are rich enough in uranium to apply the ${ }^{234} \mathrm{U}^{230} \mathrm{Th}$ disequilibrium method with relatively high precision even for near modern samples. The uranium concentrations are in the same range as those found in the aragonite skeletons of most hermatypic and ahermatypic corals, which are between 2 and $5 \mu \mathrm{g} \mathrm{g}^{-1}$ (Burnett and Veeh, 1992; Stein et al., 1991; Mangini et al., 1998; Lomitschka and Mangini, 1999; Goldstein et al., 2001; Yu et al., 2006). For this species of deep-sea coral, U-series dating is possible using a relatively small amount of carbonate 
$(70 \pm 15 \mathrm{mg}$ ), with final uncertainties being only $3-5$ years. For older (i.e., 200-300 year-old) this is equivalent to uncertainties of several percent.

The application of the ${ }^{234} \mathrm{U}_{-}{ }^{230} \mathrm{Th}$ disequilibrium dating method also provides an age profiles for individual specimens of E. rostrata. For these profiles, the age of the outer part of the basal sampling disk would be expected to be near zero, but the ages found are between 26 and 136 years old for P4-114-14 and P4-146-3, respectively. This indicates that the specimens of E. rostrata are no longer calcifying or thickening at the base, or at least at a much reduced rate during the last $\sim 30$ to 140 years for the basal sections that we have analyzed. We propose that in addition to 'averaging' in time due to low radial extension rates, the basal portions have substantially reduced calcification being relatively remote from the polyps and the more 'active' areas of calcification. This implies coral is conserving its 'energy' and/or the efficiency of calcification in the older basal tissue is substantially reduced. This hypothesis is consistent with the $\mathrm{Th} / \mathrm{U}$-ages measured on the external branch of a specimen collected off Jarvis Island at $532 \mathrm{~m}$ depth (specimen P4-144-14). The actively growing polyp has a Th/U-age of $6 \pm 5$ years old (point A, Fig. $5 \mathrm{c}$ ) whereas the outermost portion of the base (\#2) has an age of $26 \pm 1$ years. This result implies that the tips of the branches are younger than the outer parts of the basal portions. In our model of growth colonies of E. rostrata would stop accreting carbonate around the basal part when they reach a certain size and or age, but they would keep growing in their upper parts. This may impose a practical limit to the
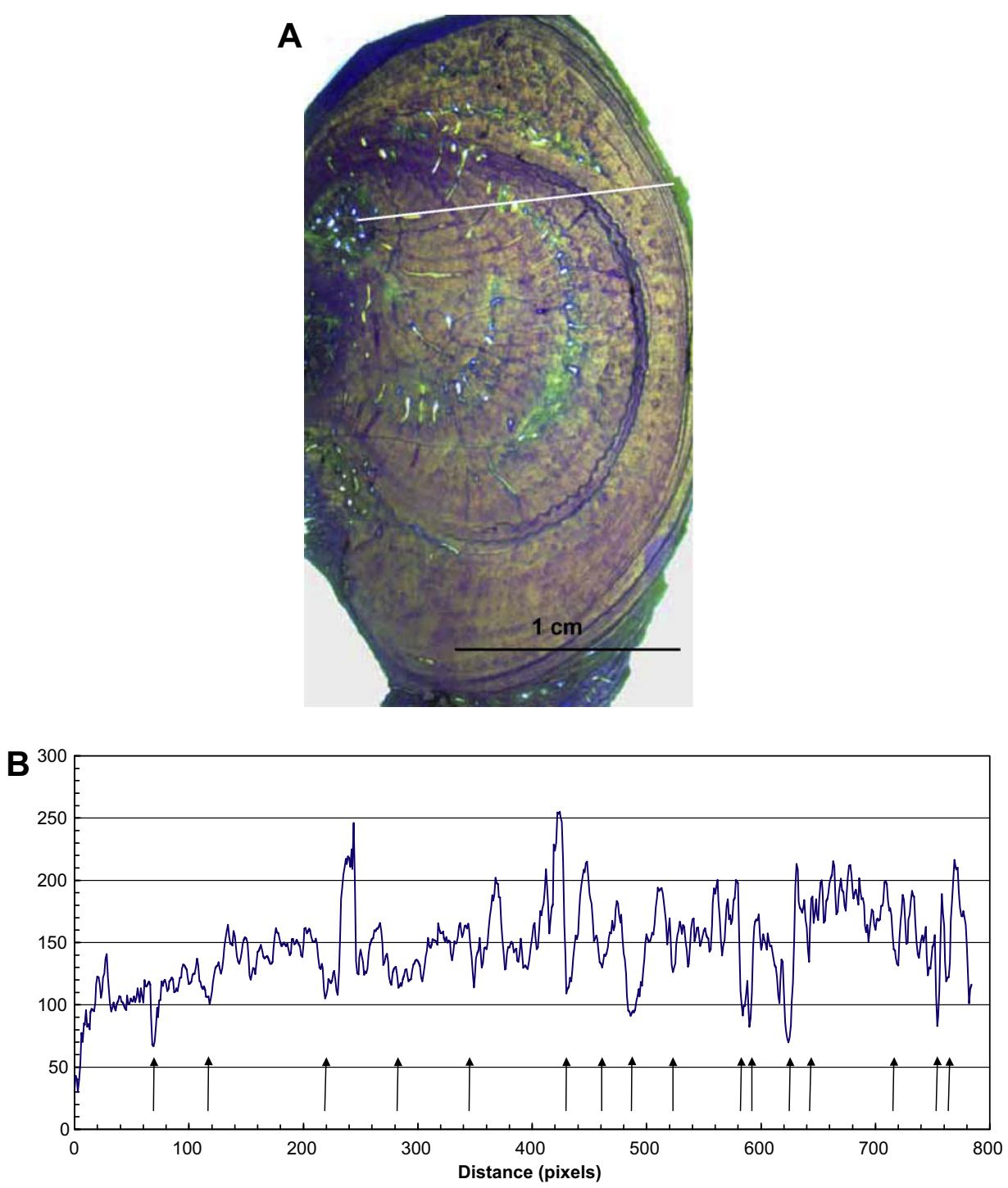

Fig. 7. (A) Microscopy image with transmitted light of one disk of sample P4-144-14 (12.5×). Organic matrix has been stained with Toluidine blue, making appear the banding in the cross-section. (B) Gray scale variation across three radial lines, represented by a white line on (a) (only one radial line has been represented). Black arrows indicate density bands. For each radial line, there are $<16-18$ bands. This specimen is 218 years old. This sample shows an average of one band about every 20 years. 
size of the specimens: when they become too large and top heavy they could shear off as well as being limited in size by the ongoing effects of bioerosion of the basal stem

Measurements of ${ }^{238} \mathrm{U}^{230} \mathrm{Th}$ activity on these five samples of E. rostrata collected from $480 \mathrm{~m}$ to $788 \mathrm{~m}$ depth at three different stations in the Equatorial Pacific yields a mean radial growth equal to $0.047 \pm 0.014 \mathrm{~mm} \mathrm{yr}^{-1}$. This value is in the same range, but slightly lower, than the growth rate of $0.07 \mathrm{~mm} \mathrm{yr}^{-1}$, reported by Adkins et al. (2004) on a single Atlantic sample of E. rostrata, using the ${ }^{210} \mathrm{~Pb}-{ }^{226} \mathrm{Ra}$ technique.

One of the most important results is that the species $E$. rostrata is a long-lived colonial organism, which can attain ages of 605 years. The maximum age calculated here is not from the tallest colony that has been recorded, suggesting that E. rostrata may attain ages exceeding this estimate. Using U-Th series dating, Cheng et al. (2000) determined ages from a set of $D$. cristagalli specimens of from 7 to 535 years old. ${ }^{234} \mathrm{U}^{2}{ }^{230} \mathrm{Th}$ ratio measurements on a sample of $L$. pertusa from the eastern Atlantic yield ages of 86 to 92 years (Pons-Branchu et al., 2005). Among these deepsea scleractinian species, E. rostrata, on average is among the longer-lived colonial organisms and exhibit as much as 6-fold greater life span compared to L. pertusa.

Deep-sea Scleractinian species have different vertical extension rates, depending of the species (from $0.1 \mathrm{~mm} \mathrm{yr}^{-1}$ for D. cristagalli up to $9.4 \mathrm{~mm} \mathrm{yr}^{-1}$ for L. pertusa) (Cheng et al., 2000; Mortensen et al., 2001). These growth rates are generally much lower than in tropical corals, showing growth rates ranging from 6 to $19 \mathrm{~mm} \mathrm{yr}^{-1}$ for massive forms (like for example Porites sp.) to $21-44 \mathrm{~mm} \mathrm{yr}^{-1}$ for ramose forms (like Pocillopora damicornis) (e.g., Hubbard and Scaturo, 1985; Huston, 1985; Guzman and Cortes, 1989). The vertical extension rates calculated for our five specimens of $E$. rostrata are lower (between 0.6 and $1.9 \mathrm{~mm} \mathrm{yr}^{-1}$ ) than the maximal extension rate of $\sim 5 \mathrm{~mm} \mathrm{yr}^{-1}$, calculated by Adkins et al. (2004). According to Adkins et al. (2004), the deep-sea Scleractinian corals Lophelia sp. and E. rostrata extend faster than the species D. cristagalli (showing an extension rate of $0.5-$ $2.0 \mathrm{~mm} \mathrm{yr}^{-1}$ ). However in our study, we found for $E$. rostrata a vertical extension rate equivalent to $D$. cristagalli and smaller than $L$. pertusa, for which U-series measurements gave mean growth rates between 2.2 and $5.0 \mathrm{~mm} \mathrm{yr}^{-1}$ (Pons-Branchu et al., 2005). Orejas et al. (2007) found higher linear extension rates for branches of specimens of $L$. pertusa and $M$. oculata maintained in aquaria (15$17 \mathrm{~mm} \mathrm{yr}^{-1}$ and between 3 and $18 \mathrm{~mm} \mathrm{yr}^{-1}$, respectively) than for E. rostrata. Compared to 'gorgonian' deep-sea corals, the scleractinian E. rostrata belongs to the category of the long-lived organisms like Gerardia sp. (gold coral order Antipatharia) or Leiopathes sp. (Black coral order Antipatharia), for which radial growth rates as low as 4 $35 \mu \mathrm{m}^{-1}$ and individual colony longevities on the order of thousand of years have been calculated using radiocarbon measurements (Roark et al., 2006, 2009). Slow growth rates and great longevity make $E$. rostrata especially vulnerable to disturbances and impacts from climate change and anthropogenic activities. Knowledge about age and growth rates of deep-sea corals is important background for assessing their vulnerability to damages from human activities.

Annual growth bands are thought to form in some deepsea corals and have been counted to estimate or infer age (Grigg, 1974; Mitchell et al., 1993; Mistri and Ceccherelli, 1994; Sherwood et al., 2005). In our study, the growth ring pattern is not consistent with annual periodicity and indicates the importance of absolute radiometric dating methods to constrain the growth rates of E. rostrata. The development of $E$. rostrata appears more discontinuous compared to other deep-sea Scleractinian corals like Desmophyllum and Lophelia, which show regular growth band patterns (Spiro et al., 2000; Cheng et al., 2000; Adkins et al., 2004). The varying thickness and the deposition rhythm of this banding have been shown to be governed by endogeneous physiological rhythms (Emiliani et al., 1978) or by the raining food supply from above (Deuser et al., 1981; Sherwood et al., 2005). With respect to E. rostrata colonies, we hypothesize that variations in their food supply may be an important controlling factor on the formation of their irregular skeletal growth bands.

The colonies of $E$. rostrata found around the Line Islands exhibit two different morphologies: a heavily calcified thick branching structure (called morphotype 1) and a more fragile form with thinner branches and a more bushy structure (called morphotype 2). Both morphotypes can reach approximately the same wingspan $(34.3-42.3 \mathrm{~cm})$. Deepsea corals commonly occur in benthic habitats that are subject to persistent currents and the function of coral skeleton is essentially to provide efficient filtering of food particles but also to withstand these strong currents (Mortensen and Buhl-Mortensen, 2005). The intensity and the variability of the currents is a potential force influencing coral growth and ramification rates (Weinbauer and Velimirov, 1995). Depending of their locations, these two different types of E. rostrata colonies would experience different microhabitats. For example, it has been demonstrated for gorgonians from shallow waters, that when there is no dominant current direction, their morphology is typically bushy, whereas regions with strong and unidirectional currents will tend to support colonies with concave fans (Theodor, 1963; Grigg, 1972). Weinbauer and Velimirov (1995) showed that gorgonian colonies from extremely sheltered and very exposed habitats have very porous (spaced) branching networks with long branches and few ramifications compared to colonies from intermediate habitats, which are characterized by strongly ramified branches with low porosity values. So we could assume that to achieve the skeletal support to withstand the water movement, $E$. rostrata would develop a much thicker trunk as well as fewer compact branches (morphotype 1, Fig. 2a) while they would develop a more bushy and fragile structure (morphotype 2, Fig. 3a) when submitted to intermediate conditions. Although no current measurements have been done around these colonies of E. rostrata to confirm these hypotheses, $E$. rostrata may have some potential as indicators of local near-bottom current patterns.

For both colony types, a significant difference in polyp density has been found between both sides of the colony (Fig. 3a and b). This may indicate that only one side is 
important for particle capture. The differences in the shape and size of the polyps as well as in their density probably reflect different adaptations for feeding or (size of) food sources. In the colonies of morphotype (2) (Fig. 3a), the repartition of polyps is uniform but in the colonies of morphotype (1) (Fig. 2a), polyps are concentrated on the branches implying that, feeding is mainly taking place in parts of the colony where the water flow is highest.

The three specimens of morphotype 2 show a preferential radial growth axis, exhibiting growth rates 2-4 times higher than on the opposite side. This pattern does not exist for the two specimens of morphotype 1. For this morphotype, "old" tips might have been embedded in the growing skeleton and could appear as "new trunk" in the cross-section disks. This may account for the disruptions observed in the $\mathrm{Th} / \mathrm{U}$-ages profile. These interfering polyps lead to changes in the banding pattern across a basal disk and can give the impression that the growth starts simultaneously in the different parts of the branches. Apparently there is no change in the growth rates between the heavily calcified morphotype (1) and morphotype (2). However, additional analyses on a greater number of specimens would be necessary to confirm this result. No differences in growth rates has been found either according to the depth or the sampling station but further studies are necessary to examine variability in growth in relation to environmental conditions.

The presence of deep-sea corals is conditioned by many environmental parameters. Deep-sea corals are largely restricted to oceanic waters and temperatures between $4{ }^{\circ} \mathrm{C}$ and $12{ }^{\circ} \mathrm{C}$, these conditions are generally found in relatively shallow waters ( $\sim 50$ to $1000 \mathrm{~m})$ at high latitudes, and at great depths (up to $4000 \mathrm{~m}$ ) beneath warm water masses at low latitudes (Roberts et al., 2006). They need specific hydrodynamic and food supply conditions to favor their growth. Recent research shows that cold-water corals are fueled by primary productivity in surface waters and subsequent food transport to the sea floor (Duineveld et al., 2004). There is increasing interest in the development of biogeochemical proxy records of climatic and environmental changes contained in the skeletons of these deep-sea corals (Roark et al., 2005). The development of paleoclimate proxy reconstructions both require the precise determination of coral ages and growth rates. These results presented here, which include longevity, growth patterns and growth rates in E. rostrata provide a fundamental baseline for deep-water ecological studies and demonstrate the potential to use this species as paleoceanographic archive.

\section{CONCLUSIONS}

Measurements of ${ }^{230} \mathrm{Th} /{ }^{238} \mathrm{U}$ activity on the five samples of $E$. rostrata showed that this species is a long-lived colonial organism, which can attain ages of at least 605 years. Compared to other deep-sea scleractinian coral, E. rostrata, on average, is among the longest-lived organisms and exhibit as much as 6-fold greater life span compared to L. pertusa. This species revealed a mean radial growth of $0.047 \pm 0.014 \mathrm{~mm} \mathrm{yr}^{-1}$ and vertical extension rates ranging from 0.6 to $1.9 \mathrm{~mm} \mathrm{yr}^{-1}$, equivalent to growth rates esti- mated for D. cristagalli but slower than those estimated for L. pertusa. According to the Th/U-age profile obtained in the basal disks and in some branches, colonies of $E$. rostrata stop accreting carbonate around the basal part when they reach a certain size, but keep growing in the upper parts.

Development of E. rostrata appeared more discontinuous than the other deep-sea scleractinian corals and its growth ring pattern is not consistent with annual periodicity and indicates the importance of absolute radiometric dating methods to constrain the growth rates of this species.

\section{ACKNOWLEDGMENTS}

This work was funded by a fellowship from Stanford University and by a Lavoisier Fellowship from the French Ministry of Foreign Affairs. We especially thank Bob Jones for assistance with SEM imaging in Stanford University. The NOAA Hawai'ian Undersea Research Laboratory funded ship time and submersible resources. Field and logistical supports were provided by The National Geographic Society (CRE: 7717-04). Analytical and additional supports were provided by the National Science Foundation (OCE0551792 and OCE-0551481). We also gratefully acknowledge the support provided by the Australian Research Council to Malcolm McCulloch and Robert Dunbar from Grants DP0559042 and DP0986505. We would like to thank Dr. Stephen Cairns (Smithsonian Institution, Washington) for the identification of the specimens and Christian Marschal for helping us in this study. Thanks are due to four anonymous reviewers for the helpful comments and constructive remarks on this paper.

\section{REFERENCES}

Adkins J. F., Cheng H., Boyle E. A., Druffel E. R. M. and Edwards R. L. (1998) Deep-sea coral evidence for rapid change in ventilation of the deep North Atlantic 15, 400 years ago. Science 280, 725-728.

Adkins J. F., Griffin S., Kashgarian M., Cheng H., Druffel E. R. M., Boyle E. A., Edwards R. L. and Shen C. (2002) Radiocarbon dating of deep-sea corals. Radiocarbon 44, 567-580.

Adkins J. F., Henderson G. M., Wang S. L., O'Shea S. and Mokadem F. (2004) Growth rates of the deep-sea scleractinia Desmophyllum cristagalli and Enallopsammia rostrata. Earth Planet. Sci. Lett. 227(3-4), 481-490.

Albarède F., Telouk P., Blichert-Toft J., Boyet M., Agranier A. and Nelson B. (2004) Precise and accurate isotopic measurements using multi-collector ICPMS. Geochim. Cosmochim. Acta 68, 2725-2744.

Andrews A. H., Cordes E. E., Mahoney M. M., Munk K., Coale K. H., Cailliet G. M. and Heifetz J. (2002) Age, growth and radiometric age validation of a deep-sea habitat-forming gorgonian (Primnoa resedaeformis) from the Gulf of Alaska. Hydrobiology 471, 101-110.

Bard E., Harmelin B. and Fairbanks R. G. (1990) U-Th ages obtained by mass-spectrometry in corals from Barbados: sea level during the past 130000 years. Nature 346(6283), 456-458.

Bell B. and Smith J. (1999) Coral growing on North Sea oil rigs. Nature 402, 601.

Bett B. J. (2001) UK Atlantic Margin environmental survey: introduction and overview of bathyal benthic ecology. Cont. Shelf Res. 21, 917-956.

Broecker W. S. and Thurber D. L. (1965) Uranium-Series dating of corals and oolites from Bahaman and Florida key limestones. Science 149, 58-60. 
Babcock S. N. and Burgess R. C. (2006) Reproductive ecology of three reef-forming, deep-sea corals in the New-Zealand region. In Cold-water Corals and Ecosystems (eds. J. M. Roberts and A. Freiwald). Springer-Verlag, Berlin Heidelberg, pp. 701-713.

Burnett W. C. and Veeh H. H. (1992) Uranium-series studies of marine phosphate and carbonates. In Uranium-series disequilibrium: Applications to Earth, Marine and Environmental Sciences (second edition) (eds. M. Ivanovich and R. S. Harmon). Clarendon Press, Oxford, pp. 487-512.

Cairns S. D. (1984) New records of ahermatypic corals (Scleractinia) from the Hawaiian and Line Islands. Occasional Papers of the Bernice Pauahi Bishop Museum 25(10), 1-30.

Cairns S. D. (1995) The marine fauna of New Zealand: Scleractinia (Cnidaria: Anthozoa). N Z Oceanogr. Inst. Memoir 103.

Cheng H., Adkins J., Edwards R. L. and Boyle E. A. (2000) U-Th dating of deep-sea corals. Geochim. Cosmochim. Acta 64, 24012416.

Delanghe D., Bard E. and Hamelin B. (2002) New TIMS constraints on the uranium-238 and uranium-234 in seawaters from the main ocean basins and the Mediterranean Sea. Mar. Chem. 80, 79-93.

Deuser W. G., Ross E. H. and Anderson R. F. (1981) Seasonality in the supply of sediment in the deep Sargasso Sea and implications for the rapid transfer of matter to the deep ocean. Deep-Sea Res. 28, 495-505.

Druffel E. R. M., King L. L., Belastock R. A. and Buesseler K. O. (1990) Growth-rate of a deep-sea coral using Pb-210 and other isotopes. Geochim. Cosmochim. Acta 54(5), 1493-1500.

Druffel E. R. M., Griffin S., Witter A., Nelson E., Southon J., Kashgarian M. and Vogel J. (1995) Gerardia - Bristlecone-Pine of the deep-sea. Geochim. Cosm. Acta 59(23), 5031-5036.

Duineveld G. C. A., Lavaleye M. S. S. and Berghuis E. M. (2004) Particle flux and food supply to a seamount cold-water coral community (Galicia Bank, NW Spain). Mar. Ecol. Prog. Ser. 277, 13-23.

Duncan P. M. (1877) - On the rapidity of growth and variability of some Madreporaria on an Atlantic cable with remarks upon the rate of accumulation of foraminiferal deposits. Ann. Mag. Nat. Hist. 20, 361-365.

Edwards R. L., Chen J. H., Ku T. L. and Wasserburg G. J. (1987) Precise timing of the last interglacial period from mass spectrometric determination of thorium-230 in corals. Science 236, 1547-1553.

Edwards R. L., Gallup and Cheng H. (2003) Uranium-series dating of marine and lacustrine carbonates. Rev. Min. Geoch. 52, 363405.

Emiliani C., Hudson J. H., Shinn E. A. and George R. Y. (1978) Oxygen and carbon isotopic growth record in a reef coral from the Florida Keys and a deep-sea coral from Blake plateau. Science 202(4368), 627-629.

Fairbanks R. G. and Dodge R. E. (1979) Annual periodicity of the ${ }^{18} \mathrm{O} /{ }^{16} \mathrm{O}$ and ${ }^{13} \mathrm{C} /{ }^{12} \mathrm{C}$ ratios in the coral Montastrea annularis. Geochim. Cosmochim. Acta 43, 1009-1020.

Freiwald A., Fossa J. H., Grehan A., Koslow T. and Roberts M. (2004) Cold-water Coral Reefs. UNEP-WCMC, Cambridge, UK. pp. 86.

Goldstein S. J., Lea D. W., Chakraborty S., Kashgarian M. and Murrell M. T. (2001) Uranium-series and radiocarbon geochronology of deep-sea corals: implications for Southern Ocean ventilation rates and the oceanic carbon cycle. Earth Planet. Sci. Lett. 193, 167-182.

Grigg R. W. (1972) Orientation and growth form of sea fans. Limnol. Oceanogr. 17(2), 185-192.

Grigg R. W. (1974) Growth rings: annual periodicity in two gorgonian corals. Ecology 55, 876-881.
Grigg R. W. (1977) Population-dynamics of two gorgonian corals. Ecology 58(2), 278-290.

Guinotte J. M., Orr J., Cairns S., Freiwald A., Morgan L. and George R. (2006) Will human-induced changes in seawater chemistry alter the distribution of deep-sea scleractinian corals? Front. Ecol. Environ. 4(3), 141-146.

Guzman H. M. and Cortes J. (1989) Coral reef community structure at Cano Island. Pacific Costa Rica. Mar. Ecol. 10(1), 23-41.

Halliday A. N., Lee D. C., Christensen J. N., Walder A. J., Freedman P. A., Jones C. E., Hall C. M., Yi W. and Teagle D. (1995) Recent developments in inductively coupled plasma magnetic sector multiple collector mass spectrometry. Int. J. Mass Spec. Ion Proc. 146(147), 21-33.

Hall-Spencer J., Allain V. and Fossa J. H. (2002) Trawling damage to Northeast Atlantic ancient coral reefs. Proc. R. Soc. Lond. Ser. B: Biol. Sci. 269, 507-511.

Heikoop J. M., Hickmott D. D., Risk M. J., Shearer C. K. and Atudorei V. (2002) Potential climate signal from the deep-sea gorgonian coral Primnoa resedaeformis. Hydrobiology 471, 117124.

Hellstrom J. (2003) Rapid and accurate U/Th dating using parallel ion-counting multi-collector ICP-MS. J. Anal. Atomic Spectrom. 18, 1346-1351.

Hubbard D. K. and Scaturo D. (1985) Growth rates of seven species of Scleractinian corals form Cane Bay and Salt River, St. Croix USVI. Bull. Mar. Sci. 36(2), 325-338.

Huston M. (1985) Variation on coral growth rates with depth at Discovery Bay, Jamaica. Coral Reefs 4(1), 19-25.

ICES (2004) Report of the Study Group on Cold-Water Corals (SGCOR). International Council for the Exploration of the Sea. ICES CM 2004IACE:07 Ref. E.

Jaffrey A. H., Flynn K. F., Glendenin L. E., Bentley W. C. and Essling A. M. (1971) Precision measurement of half-lives and specific activities of ${ }^{235} \mathrm{U}$ and ${ }^{238} \mathrm{U}$. Phys. Rev. C 4, 1889-1906.

Koslow J. A. and Gowlett-Jones K. (1998) The seamount fauna off Southern Tasmania: benthic communities, their conservation and impacts of trawling. Final Rep. Environ. Australia Fish Res. Dev. Corp. Australia, 104pp.

Lomitschka M. and Mangini A. (1999) Precise U/Th dating of small and heavily coated samples of deep sea corals. Earth Planet. Sci. Lett. 170, 391-401.

Luo X., Rehkamber M., Lee D. C. and Halliday A. N. (1997) High precision ${ }^{230} \mathrm{Th} /{ }^{238} \mathrm{U}$ and ${ }^{234} \mathrm{U} /{ }^{238} \mathrm{U}$ measurements using energy-filtered ICP magnetic sector multiple collector mass spectrometry. Int. J. Mass Spec. Ion Proc. 171, 105-117.

Maier C., Hegeman J., Weinbauer M. G. and Gattuso J. P. (2009) Calcification of the cold-water coral Lophelia pertusa, under ambient and reduced pH. Biogeosciences 6, 1671-1680.

Mangini A., Lomitschka M., Eichstadter R., Frank N., Vogler S., Bonani G., Hajdas I. and Patzold J. (1998) Corals provide way to age deep water. Nature 392, 347-348.

Marshall N. B. (1979) Deep-sea Biology: Developments and Perspectives. Garland STPM Press, New-York, 566 pp.

Marschal C., Garrabou J., Harmelin J. G. and Pichon M. (2004) A new method for measuring growth and age in the precious red coral Corallium rubrum (L.). Coral Reefs 23, 423-432.

McCulloch M. T. and Mortimer G. E. (2008) Applications of the $238 \mathrm{U}-230 \mathrm{Th}$ decay series to dating of fossil and modern corals using MC-ICPMS. Aust. J. Earth Sci. 55(6), 955-965.

Mistri M. and Ceccherelli V. U. (1994) Growth and secondary production of the Mediterranean gorgonian. Paramuricea clavata. Mar. Ecol. Prog. Ser. 103, 291-296.

Mitchell N. D., Dardeau M. R. and Shroeder W. W. (1993) Colony morphology, age structure and relative growth of two gorgonian corals, Leptogorgia hebes (Verrill) and Leptogorgia 
virgulata (Lamarck), from the northern Gulf of Mexico. Coral Reefs 12, 65-70.

Montagna P., McCulloch M., Taviani M., Mazzoli C. and Vendrell B. (2006) Phosphorus in cold-water corals as a proxy for seawater nutrient chemistry. Science 312(5781), 1788-1791.

Mortensen P. B., Hovland M., Brattegard T. and Farestveit (1995) Deep-water bioherms of the scleractinian coral Lophelia pertusa (L.) at $64 \mathrm{~N}$ on the Norwegian shelf: structure and associated megafauna. Sarsia 80, 145-158.

Mortensen P. B., Hovland T., Helge Fossa J. and Furevik D. M. (2001) Distribution, abundance and size of Lophelia pertusa coral reefs in mid-Norway in relation to seabed characteristics. J. Mar. Assoc. UK 81(4), 581-597.

Mortensen P. B. and Buhl-Mortensen L. (2005) Morphology and growth of the deep-water gorgonians Primnoa resedaeformis and Paragorgia arborea. Mar. Biol. 147, 775-788.

Noé S. U. and Dullo W. C. (2006) Skeletal morphogenesis and growth mode of modern and fossil deep-water isidid gorgonians (Octocorallia) in the West Pacific (New Zealand and Sea of Okhotsk). Coral Reefs 25(3), 303-320.

Omura A. (1983) - Oxygen and carbon isotopic composition in the skeleton of and hermatypic scleractinian coral, Dendrophyllia japonica. Trans. Proc. Paleontol. Soc. Jpn. 131, 159-167.

Orejas C., Gori A. and Gili J. M. (2007) Growth rates of live Lophelia pertusa and Madrepora oculata from the Mediterranean Sea maintained in aquaria. Coral Reefs 27(2), 255, $-255(1)$.

Orr J. C., Fabry V. J., Aumont O., Bopp L., Doney S. C., Feely R. A., Gnanadesikan A., Gruber N., Ishida A., Joos F., Key R. M., Lindsay K., Maier-Reimer E., Matear R., Monfray P., Mouchet A., Najjar R. G., Plattner G.-K., Rodgers K., Sabine C. L., Sarmiento J. L., Schlitzer R., Slater R. D., Totterdell I. J., Weirig M. F., Yamanaka Y. and Yool A. (2005) Anthropogenic ocean acidification over the twenty-first century and its impact on calcifying organisms. Nature 437, 681-686.

Packer D. B., Boelke D., Guida V. and McGee L. A. (2007) State of deep coral ecosystems in the Northeastern US region: Maine to Cape Hatteras. In The State of Deep Coral Ecosystems of the United States (eds. S. E. Lumsden, T. F. Hourigan, A. W. Bruckner and G. Dorr). NOAA Technical Memorandum CRCP-3, Silver Spring MD, pp. 195-232.

Parrish F. A. and Baco A. R. (2007) State of deep coral ecosystems in the U.S. Pacific Islands Region: Hawaii and the U.S. Pacific territories. In The State of Deep Coral Ecosystems of the United States (eds. S. E. Lumsden, T. F. Hourigan, A. W. Bruckner and G. Dorr). NOAA Technical Memorandum CRCP-3, Silver Spring, MD, pp. 155-193, 365pp..

Pons-Branchu E., Hillaire-Marcel C., Deschamps P., Ghaler B. and Sinclair D. (2005) Early diagenesis impact on precise U-series dating of deep-sea corals: example of a 100-200-year old Lophelia pertusa samples from the northeast Atlantic. Geochem. Acta 69(20), 4865-4879.

Pourtalès L. F. (1878) Report on the corals of the "Blake" expedition. Bull. Mus. Comp. Zool. Harvard Univ. 5, 197-212.

Probert P. K., Mc Knight D. G. and Grove S. L. (1997) Benthic invertebrate bycatch from a deep-water trawl fishery, Chathman Rise, New Zealand. Aquatic conservation. Mar. Freshwater Ecosyst. 7, 27-40.

Reed J. K. and Ross S. W. (2005) Deep-water reefs off the Southern U.S.: recent discoveries and research. J. Mar. Edu. 21(4), 33-37.

Risk M. J., McAllister D. E. and Behnken L. (1998) Conservation of cold- and warm-water seafans: threatened ancient gorgonian groves. Sea Wind 12(1), 2-21.

Risk M. J., Heikoop J. M., Snow M. G. and Beukens R. (2002) Lifespans and growth patterns of two deep-sea corals: Primnoa resedaeformis and Desmophyllum cristagalli. Hydrobiology 471, $125-131$.

Roark E. B., Guilderson T. P., Flood-Page S. R., Dunbar R. B., Ingram B. L., Fallon S. J. and Mc Culloch M. T. (2005) Radiocarbon-based ages and growth rates for bamboo corals from the Gulf of Alaska. Geophys. Res. Lett. 32, 1-5.

Roark E. B., Guilderson T., Dunbar R. B. and Ingram B. L. (2006) Radiocarbon-based ages and growth rates of Hawaiian deepsea corals. Mar. Ecol. Prog. Ser. 327, 1-14.

Roark E. B., Guilderson T. P., Dunbar R. B., Fallon S. J. and Mucciarone D. A. (2009) Extreme longevity in proteinaceous deep-sea corals. Proc. Nat. Acad. Sci. 106(13), 5204-5208.

Roberts J. M., Brown C. J., Long D. and Bates C. R. (2005) Acoustic mapping using a multibeam echosounder reveals coldwater coral reefs and surrounding habitats. Coral Reefs 24, 654.

Roberts J. M., Wheeler A. J. and Freiwald A. (2006) Reefs of the deep: the biology and geology of cold-water coral ecosystems. Science 312, 543-547.

Robinson L. F., Belshaw N. S. and Henderson G. M. (2004) U and Th concentrations and isotope ratios in modern carbonates and waters from the Bahamas. Geochim. Cosmochim. Acta 68(8), 1777-1789.

Rogers A. D. (1999) The biology of Lophelia pertusa (L. 1758) and other deep-water reef-forming corals and impacts from human activities. Int. Rev. Hydrobiol. 84, 315-406.

Ross S. W. and Nizinski M. S. (2007) State of deep coral ecosystems in the U.S Southeast region: Cape Hatteras to Southeastern Florida. In The State of Deep Coral Ecosystems of the United States (eds. S. E. Lumsden, T. F. Hourigan, A. W. Dorr and G. Bruckner). NOAA Technical Memorandum CRCP-3, Silver Spring, MD, pp. 233-269, 365pp..

Seth B., Thirlwall M. F., Houghton S. L. and Craig C. A. (2003) Accurate measurements of the Th-U isotope ratios for carbonate geochronology using MC-ICP-MS. J. Anal. Atomic Spectrom. 18, 1323-1330.

Shen C. C., Li K. S., Sieh K., Natawidjaja D., Cheng H., Wang X., Edwards R. L., Lam D. D., Hsieh Y. T., Fan T. Y., Meltzner A. J., Taylor F. W., Quinn T. M., Chiang H. W. and Kilbourne K. H. (2008) Variation of initial ${ }^{230} \mathrm{Th} /{ }^{232} \mathrm{Th}$ and limits of high precision U-Th dating of shallow-water corals. Geochim. Cosmochem. Acta 72, 4201-4223.

Sherwood O. A., Scott D. B., Risk M. J. and Guilderson T. P. (2005) Radiocarbon evidence for annual growth rings in the deep-sea octocoral Primnoa resedaeformis. Mar. Ecol. Prog. Ser. 301, 129-134.

Smith J. E., Schwarcz H. P., Risk M. J., McConnaughey T. A. and Keller N. (2000) Paleotemperatures from deep-sea corals: overcoming 'vital effects'. Palaios 15(1), 25-32.

Spiro B., Roberts M., Gage J. and Chenery S. (2000) ${ }^{18} \mathrm{O} /{ }^{16} \mathrm{O}$ and ${ }^{13} \mathrm{C} /{ }^{12} \mathrm{C}$ in an ahermatypic deep-water coral Lophelia pertusa from the North Atlantic: a case of disequilibrium isotope fractionation. Rap. Commun. Mass Spectrom. 14, 1332-1336.

Stein M., Wasserburg G. J., Lajoie K. R. and Chen J. H. (1991) Useries ages of solitary corals from the California Coast by massspectrometry. Geochim. Cosmochim. Acta 55(12), 3709-3722.

Theodor J. (1963) Contribution à l'étude des gorgones, 3. Vie Milieu 14, 815-818.

Thiem Ø., Ravagnan E., Fosså J. H. and Bernsten J. (2006) Food supply mechanisms for cold-water corals along a continental shelf edge. J. Mar. Syst. 60, 207-219.

Thresher R., Rintoul S. R., Koslow C., Weidman C., Adkins J. and Proctor C. (2004) Oceanic evidence of climate change in Southern Australia over the last three centuries. Geophys. Res. Lett. 31, LO7212. doi:10.1029/2003GL018869.

Weinbauer M. G. and Velimirov B. (1995) Morphological variations in the Mediterranean sea fan Eunicella cavolini (coelen- 
terate: Gorgonacea) in relation to exposure, colony size and colony region. Bull. Mar. Sci. 56(1), 283-295.

Weinbauer M. G., Brandstatter F. and Velimirov B. (2000) On the potential use of magnesium and strontium concentrations as ecological indicators in the calcite skeleton of the red coral (Corallium rubrum). Mar. Biol. 137, 801-809.

Yu H., Kaufman Y. J., Chin M., Feingold G., Remer L. A., Anderson T. L., Balkansi Y., Bellouin N., Boucher O., Christopher S., DeCola P., Kahn R., Koch D., Loeb N.,
Reddy, Schulz M., Takemura T. and Zhou M. (2006) A review of measurement-based assessment of aerosol direct radiative effects and forcing. Atmos. Chem. Phys. 6, 613-666.

Zibrowius H. (1980) Les Scléractiniaires de la Méditerranée et de l'Atlantique nord-oriental. Mémoires de l'Institut Océanographique, Monaco, 11, 1-284.

Associate editor: Dimitri A. Papanastassiou 